\title{
Radiation burden from modern radiation therapy techniques including proton therapy for breast cancer treatment - clinical implications
}

\author{
Anna Maria Flejmer
}

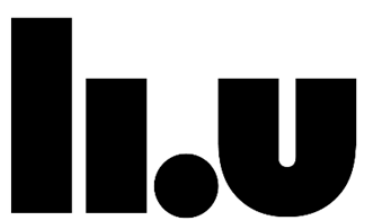

LINKÖPING UNIVERSITY

Department of Clinical and Experimental Medicine

Linköping University, Sweden Linköping 2016 
Radiation burden from modern radiation therapy techniques including proton therapy for breast cancer treatment - clinical implications

(C)Anna Maria Flejmer, 2016

Published articles have been reprinted with the permission of the copyright holders.

Printed in Sweden by LiU-Tryck, Linköping, Sweden, 2016

ISBN 978-91-7685-850-9

ISSN 0345-0082 
For people close to my heart

"Difficulties strengthen the mind, as labour does the body."

- Seneca 



\section{CONTENTS}

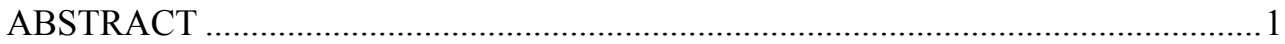

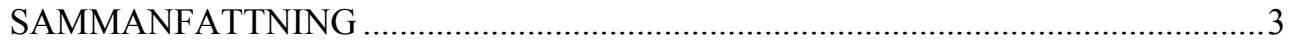

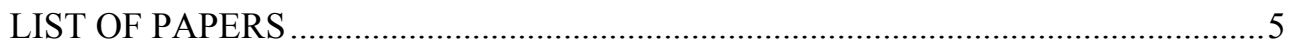

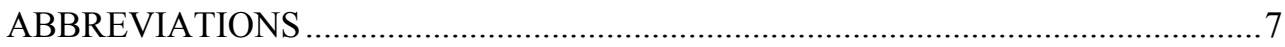

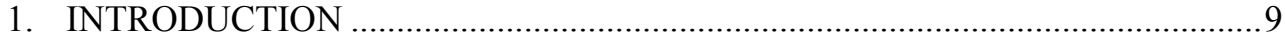

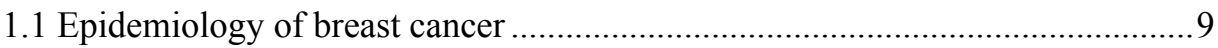

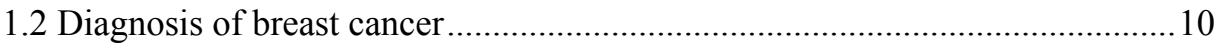

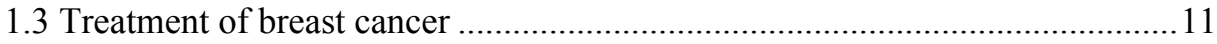

1.3.1 Surgery in breast cancer ................................................................. 11

1.3.2 Systemic therapy in breast cancer ....................................................... 11

1.3.3 Radiation therapy for breast cancer ...................................................... 12

2. MODERN RADIATION THERAPY FOR BREAST CANCER …………............15

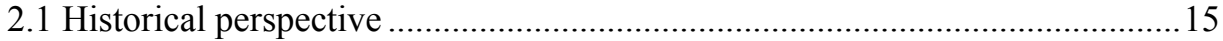

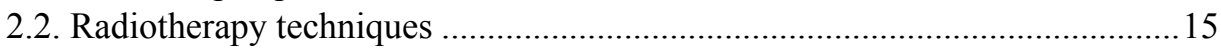

2.3. Definition of target volume for breast cancer radiotherapy .............................16

2.4. Side effects in breast cancer radiotherapy and relevant organs at risk.............17

2.5 Pathogenesis and histopathology of radiation-induced heart and coronary

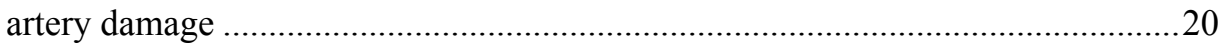

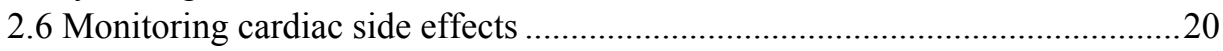

2.7 Tolerance levels and recommendations for the heart.....................................21

2.8 Pathogenesis and histopathology of radiation-induced damage to the lung ....22

2.9 Monitoring lung damage ................................................................................22

2.10 Tolerance levels and recommendations for the lung....................................23

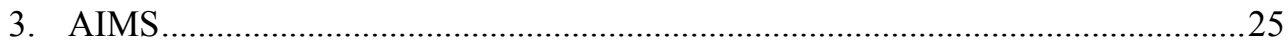

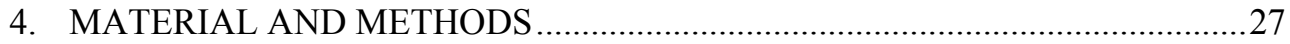

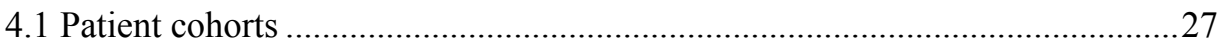

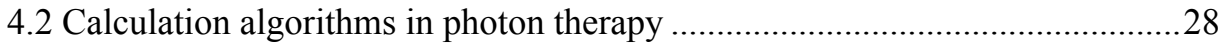

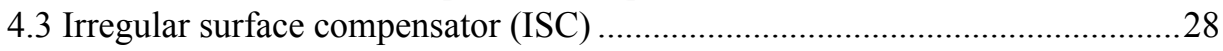




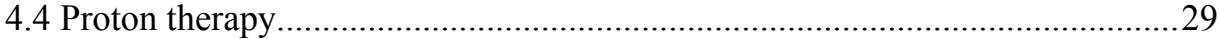

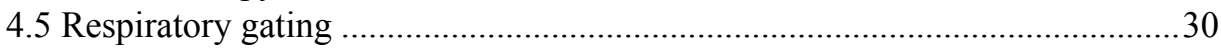

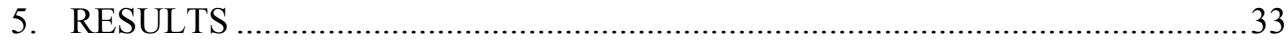

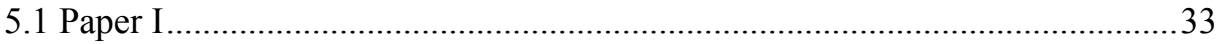

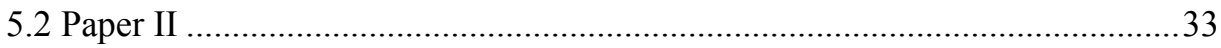

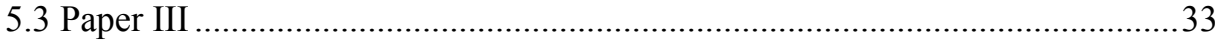

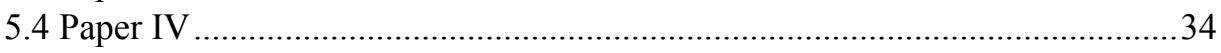

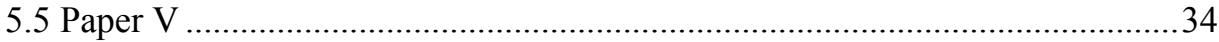

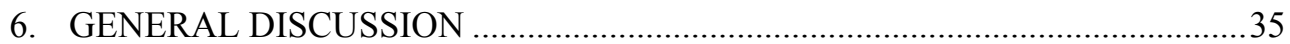

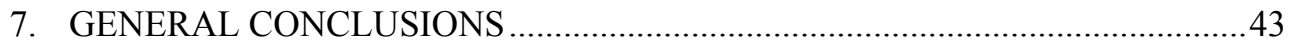

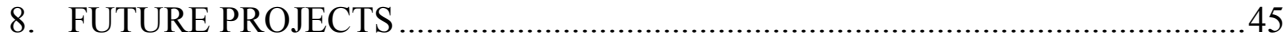

8.1 Monitoring cardiac side effects from radiotherapy to the left mammary

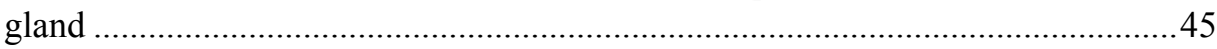

8.1.1 Patient cohort and study design ...................................................... 45

8.1.2 Monitoring heart function during treatment ...................................... 46

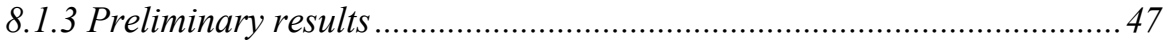

8.2 Normal tissue sparing at internal mammary nodes treatment with proton

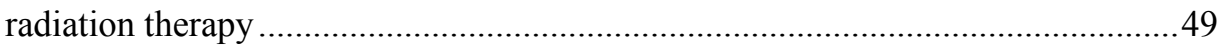

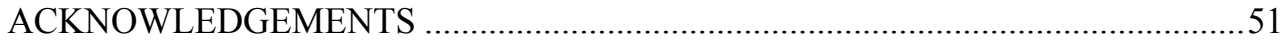

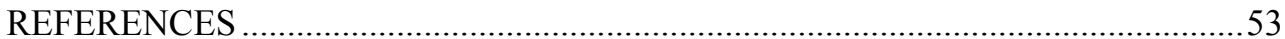




\section{ABSTRACT}

The purpose of this thesis was to study the clinical implications of modern radiotherapy techniques for breast cancer treatment. This was investigated in several individual studies.

Study I investigated the implications of using the analytical anisotropic algorithm (AAA) from the perspective of clinical recommendations for breast cancer radiotherapy. Pencil beam convolution plans of 40 breast cancer patients were recalculated with AAA. The latter plans had a significantly worse coverage of the planning target volume (PTV) with the 93\% isodose, higher maximum dose in hotspots, higher volumes of the ipsilateral lung receiving doses below $25 \mathrm{~Gy}$ and smaller volumes with doses above $25 \mathrm{~Gy}$. AAA also predicted lower doses to the heart.

Study II investigated the implications of using the irregular surface compensator (ISC), an electronic compensation algorithm, in comparison to threedimensional conformal radiotherapy (3D-CRT) for breast cancer treatment. Ten breast cancer patients were planned with both techniques. The ISC technique led to better coverage of the clinical target volume of the tumour bed (CTV-T) and PTV in almost all patients with significant improvement in homogeneity.

Study III investigated the feasibility of using scanning pencil beam proton therapy for regional and loco-regional breast cancer with comparison of ISC photon planning. Ten patients were included in the study, all with dose heterogeneity in the target and/or hotspots in the normal tissues outside the PTV. The proton plans showed comparable or better CTV-T and PTV coverage, with large reductions in the mean doses to the heart and the ipsilateral lung.

Study IV investigated the added value of enhanced inspiration gating (EIG) for proton therapy. Twenty patients were planned on CT datasets acquired during EIG and free-breathing (FB) using photon 3D-CRT and scanning proton therapy. Proton spot scanning has a high potential to reduce the irradiation of organs-atrisk for most patients, beyond what could be achieved with EIG and photon therapy, especially in terms of mean doses to the heart and the left anterior descending artery.

Study V investigated the impact of physiological breathing motion during proton radiotherapy for breast cancer. Twelve thoracic patients were planned on CT datasets during breath-hold at inhalation phase and breath-hold at exhalation phase. Between inhalation and exhalation phase there were very small differences in dose delivered to the target and cardiovascular structures, with very small clinical implication. 
The results of these studies showed the potential of various radiotherapy techniques to improve the quality of life for breast cancer patients by limiting the dose burden for normal tissues. 


\section{SAMMANFATTNING}

Projektet syfte var att studera användningen av moderna strålbehandlingstekniker för bröstcancer, med fokus på möjligheten att minska stråldosen till frisk vävnad i anslutning till den bestrålade volymen. Detta undersöktes i flera delarbeten.

Delarbete I analyserade effekten av att använda analytiska anisotrop algoritmen (AAA) för dosplanering av patienter med bröstcancer baserat på rekommendationerna från den svenska bröstcancergruppen. Dosplanering för 40 patienter med bröstcancer rekalkylerades med AAA algoritmen. Resultaten visade att strålmålet ("planning target volume" eller PTV) hade betydligt sämre täckning när AAA användes. Planering enligt AAA gav högre maximal dos i hotspots nära känsliga strukturer och förutspår högre volymer $\mathrm{i}$ den samsidiga lungan som får doser under 25 Gy och mindre volymer med doser över $25 \mathrm{~Gy}$. AAA förutspår också lägre doser till hjärtat.

Delarbete II studerade konsekvenserna av klinisk användning av en elektronisk kompensationsteknik, ISC, i jämförelse med konventionell 3D-CRT för bröstcancerbehandling. Tio patienter med bröstcancer (fem vänster- och fem högersidiga) dosplanerades med båda teknikerna. ISC tekniken ledde till betydligt bättre täckning av CTV-T ("clinical target volume of the tumour bed") och PTV hos nästan alla patienter med statistiskt signifikant bättre homogenitet av dosfördelningen. ISC medförde också en tendens till lägre volymer som bestrålas med höga doser i den samsidiga lungan vilket ledde till bättre följsamhet mot de nationella rekommendationerna för strålbehandling av bröstcancer.

Delarbete III undersökte möjligheten av att använda en skannande proton pennstråle för adjuvant strålbehandling av lokal och loko-regional bröstcancer. Tio patienter ingick i studien. Patienterna identifierades från en större grupp där dosheterogeniteten i målvolymen och/eller områden med hög stråldos i normala vävnader utanför PTV kvalificerade dem för ISC med fotoner. Proton-planerna visade jämförbara eller bättre CTV-T och PTV täckning än de ursprungliga foton-planerna. De viktigaste slutsatserna var att behandling med protonstrålning potentiellt skulle kunna betydligt minska den genomsnittliga dosen till hjärtat och den samsidiga lungan.

Delarbete IV studerade mervärdet av EIG ("enhanced inspiration gating") för protonstrålbehandling. Tjugo patienter ingick i studien. Patienterna hade planerats på CT dataunderlag under EIG och fri andning med hjälp av protonstrålning och 3D-CRT med fotonstrålning. Tio patienter hade fått behandling enbart av bröstet och tio både bröst och regionala lymfkörtlar. 
Protonbehandlingen har stor potential att minska bestrålning av strålkänslig vävnad nära målområdet utöver vad som kunnat uppnås med EIG och fotonstrålbehandling. Den viktigaste slutsatsen var att en stor potentiell minskning av genomsnittlig dos till hjärtat och det främre nedåtstigande vänstra kranskärlet var möjlig med protoner i jämförelse med fotoner.

Delarbete V undersökte effekterna av fysiologiska andningsrörelser under protonstrålbehandling. Tolv patienter planerades under olika andningsfaser och ändringar i dosfördelningar med andningsrörelser studerades. Små skillnader fanns i dosen till strålmålet och kardiovaskulära strukturer och den kliniska betydelsen förväntas vara väldigt liten.

Resultaten av dessa fem studier visar på potentialen för en förbättrad livskvalitetet för patienter med bröstcancer genom minskning av absorberad stråldos i normal vävnad. 


\section{LIST OF PAPERS}

I. Anna M. Flejmer, Frida Dohlmar, Mats Nilsson, Margaretha Stenmarker and Alexandru Dasu 2015 Analytical Anisotropic Algorithm versus Pencil Beam Convolution for treatment planning of breast cancer: implications for target coverage and radiation burden of normal tissue Anticancer Research 35:5 2841-2848

II. Anna M. Flejmer, Dan Josefsson, Mats Nilsson, Margaretha Stenmarker and Alexandru Dasu 2014 Clinical implications of the ISC technique for breast cancer radiotherapy and comparison with clinical recommendations Anticancer Research 34:7 3563-3568

III. Anna M. Flejmer, Petra Witt Nyström, Frida Dohlmar, Dan Josefsson and Alexandru Dasu 2015 Potential benefit of scanned proton beam versus photons as adjuvant radiation therapy in breast cancer International Journal of Particle Therapy 1:4 845-855

IV. Anna M. Flejmer, Anneli Edvardsson, Frida Dohlmar, Dan Josefsson, Mats Nilsson, Petra Witt Nyström and Alexandru Dasu 2016 Respiratory gating for proton beam scanning versus photon 3D-CRT for breast cancer radiotherapy Acta Oncologica (ePub ahead of print)

V. Anna M. Flejmer, Behnaz Chehrazi, Dan Josefsson, Iuliana Toma-Dasu and Alexandru Dasu Impact of physiological breathing motion for breast cancer radiotherapy with proton beam scanning (manuscript) 


\section{ABBREVIATIONS}

3D-CRT three-dimensional conformal radiotherapy

AAA

analytical anisotropic algorithm

$\mathrm{AC}$

chemotherapy employing doxorubicin and cyclophosphamide

AI

aromatase inhibitor

BRN breast and regional lymph nodes

BHE breath-hold at exhalation

BHI breath-hold at inhalation

CMF chemotherapy employing cyclophosphamide, methotrexate and fluorouracil

C-MRI cardiac magnetic resonance imaging

CT computer tomography

CTV clinical target volume

CTV-T clinical target volume of the tumour bed

DIBH deep inspiration breath hold

DLCO diffusing capacity of carbon monoxide

DVH dose volume histogram

EBCTCG Early Breast Cancer Trialists' Collaborative Group

ECG electrocardiogram

EORTC European Organisation for Research and Treatment of Cancer

EIG enhanced inspiration gating

FEC chemotherapy employing fluorouracil (5FU), epirubicin and cyclophosphamide

FEV1s forced expiratory volume in 1 second

FB free-breathing

GTV gross tumour volume

HDR high dose rate

ICRU International Commission on Radiation Units and Measurements

ITV internal target volume

IHD ischaemic heart disease

IMN internal mammary lymph nodes

IMPT intensity modulated proton therapy

IMRT intensity modulated radiation therapy

ISC irregular surface compensator 
LAD left anterior descending artery

LENT Late Effects of Normal Tissues

LDR low dose rate

LVEF left ventricular ejection fraction

MLC multileaf collimator

MRI magnetic resonance imaging

NTCP normal tissue complication probability

OAR organ at risk

QUANTEC Quantitative Analysis of Normal Tissue Effects in the Clinic

PBC pencil beam convolution

PTV planning target volume

PTV-T planning target volume of the tumour bed

PRV planned risk volume

RBE relative biological effectiveness

RT radiation therapy

RTOG Radiation Therapy Oncology Group

SOBP spread-out Bragg peak

SFUD single field uniform dose

TMN tumour, nodes, metastases classification system

TPS treatment planning system

US-SRI ultrasound-based strain rate imaging

WBO whole breast only 


\section{INTRODUCTION}

\subsection{Epidemiology of breast cancer}

Breast cancer is the most common form of cancer disease in women in Sweden and many other countries (Ferlay et al 2013, Bray et al 2013). In 2014, 9730 cases of breast cancer in women and 1422 cases with in situ tumours were registered in Sweden. The median age at diagnosis was 64 years. At the same time, about 90000 women were alive with a breast cancer diagnosis. During the last 20 years the incidence has grown with on average $1.6 \%$, accelerating to $2.6 \%$ under the last 10 years. The current cumulative risk for women to get the disease before the age of 75 is about 11\% (Regionala cancercentrum i samverkan 2014, Socialstyrelsen 2015).

Several factors can influence the appearance of breast cancer. Female sex is the main risk factor for developing breast cancer as the disease is about 100 times more common among women than men. This difference is thought to be caused by the presence of hormones like oestrogen and progesterone in women. Among women, a slightly higher risk exists for nulliparous women and for postmenopausal women that are using combined hormone therapy, with alcohol consumption and obesity as additional risk factors. Previous chest irradiation for diagnostic or therapeutic purposes, especially in younger age, is also associated with a higher risk for developing breast cancer. In contrast, multiparity and breastfeeding are associated with a reduction of the breast cancer risk. Physical activity and regular exercise could also reduce the cancer risk. However, the evidence for an association between smoking and breast cancer is very weak (IARC 2012). Working night shifts has also been implicated, increasing the risk of developing breast cancer because of changes in melatonin levels.

Genetic aspects are also important for breast cancer development. Five to ten percent of breast cancer cases are directly caused by gene defects. An inherited mutation in the BRCA1 or BRCA2 genes is the most common cause of hereditary breast cancer. The lifetime risk of developing breast cancer is $80 \%$ in some families with BRCA1 mutations, while on average the risk is in the range of 55$65 \%$. For BRCA2 the risk is around $45 \%$, but this mutation is associated with disease occurring in younger women and affecting both breasts. There are also other rare gene mutations that are associated with inherited breast cancer like ATP, TP53, CHEK2, PTEN, CDH1, STK11 and PALB2. Research continues to fully characterise inherited breast cancer (Regionala cancercentrum i samverkan 2014, American Cancer Society 2016).

Prognosis is better for this disease than for many other forms of cancer. The net survival rates of the patients have seen a positive trend in the past decades 
and currently the five year survival rate in many developed countries is around $81-86 \%$ (Walters et al 2015). In Sweden the five years survival rate is $88 \%$ and the ten year rate is approximately $80 \%$ (Engholm et al 2010, Regionala cancercentrum i samverkan 2014, Engholm et al 2015). The increased overall survival observed for breast cancer can probably be explained by advances in screening and by improved adjuvant treatment.

\subsection{Diagnosis of breast cancer}

Diagnosis of breast cancer consists of three stages. The first one is palpation of the breast, the second one is mammography and ultrasonography (for young women magnetic resonance could also be used) and the last one is biopsy. In Sweden, Socialstyrelsen recommends mammography screening for all women in the age interval 40-74 for early discovery of breast cancer (Socialstyrelsen 2016). Mammography screening is thought to reduce mortality of breast cancer with $25 \%$ for the whole population, but its effectiveness is still widely debated, especially in relation to the risk of over-diagnosis and the increase of radiation burden to the whole population. Biopsies use specially designed probes to obtain tissue samples from suspected regions to pathologically confirm the presence of cancer cells. In case the biopsy material is not suitable for pathological analyses, diagnostic resection is recommended. Sentinel lymph node biopsy is recommended for staging to determine the lymph node involvement (Regionala cancercentrum $\mathrm{i}$ samverkan 2014).

Depending on the origin of the cancer cells, a main diagnostic divider is between ductal cancers originating in the breast tubes and lobular cancers originating in the glandular tissue. The earliest form is cancer in situ, followed by invasive cancers. Invasive ductal cancer makes up the majority of invasive cancers, followed by the invasive lobular cancers. Invasive cancers could also be classified according to their invasive patterns into unifocal (with only one invasive focus), multifocal (with multiple, well defined foci, separated by healthy tissues) or diffuse (when the cancer is dispersed over a larger area, with no distinct tumour mass). Multifocality of breast cancers has been considered a negative prognostic factor (Cserni et al 2013).

All information from diagnostic procedures is used to define the stage of disease as a combination of tumour size and site (T), the spread to regional lymph nodes $(\mathrm{N})$ and other organs $(\mathrm{M})$, according to the TNM system. Treatment is recommended depending on the stage of the disease. Several other parameters from the microscopic examination like the presence of a free margin (classifies radical resection at surgery), the presence of progesterone and oestrogen receptors, the overexpression of the HER2- receptor and the proliferation marker Ki67 could also be used for deciding which systemic treatment should be recommended. There is also a functional division, based on the markers mentioned, that is helpful for risk analyses: Luminal A (Oestrogen and progesterone positive with low 
proliferation), Luminal B (hormonal positive with high proliferation), Her2positive and triple negative (HER2-negative and hormonal negative) (Goldhirsch et al 2013).

\subsection{Treatment of breast cancer}

Treatment options for the majority of the patients with breast cancer are local therapy, consisting of surgery and radiation therapy, and systemic therapy that includes chemotherapy, hormonal therapy and targeted therapy.

\subsubsection{Surgery in breast cancer}

Surgery is usually the first treatment option for breast cancer. For multifocal tumours mastectomy with adjuvant radiotherapy is still the standard of care. For unifocal tumours, with a diameter less than $5 \mathrm{~cm}$ (stage T1-T2), mastectomy as monotherapy is increasingly replaced by breast conserving surgery with adjuvant radiotherapy as a medical alternative, with comparable overall survival (Fisher et al 2002, Litiere et al 2012, Regionala cancercentrum i samverkan 2014). However there are also patients that do not undergo surgery at all, as is the case of patients with disseminated breast cancer.

The standard of care includes sentinel nodes sampling during surgery of the breast. When metastatic-positive lymph nodes are discovered, axillary lymph nodes extirpation is done. Surgery could be repeated for example when previous surgery margins are not free from cancer cells. Surgery is usually followed by systemic therapy (Morris et al 1997, Fisher et al 2002). However, when the tumour is too big for primary surgery, chemotherapy is the initial treatment followed by surgery when the tumour size has been reduced (Litiere et al 2012).

The Swedish national breast cancer program recommends mastectomy for multifocal breast cancer and for unifocal breast cancer in case of T4 tumours or in case of progress after neoadjuvant treatment, but also in case radiotherapy is contraindicated or if the surgical margin is not free from disease and even in case of negative cosmetic results. Also, the program recommends that $80 \%$ of patients should start adjuvant radiotherapy 4-5 weeks after surgery or chemotherapy. Breast reconstruction after surgery is recommended with the breast implant placed under the pectoralis muscle using an expander technique that gives better cosmetic results compared to a traditional silicone implant (Regionala cancercentrum i samverkan 2014).

\subsubsection{Systemic therapy in breast cancer}

Chemotherapy is usually prescribed after surgery as adjuvant treatment of micro-metastatic breast cancer. Assessment of the patients to be treated is based on risk analyses at group level. The predictive factors assessed are oestrogen and progesterone receptor-positivity, which is a prerequisite for the effect of endo- 
crine therapy, and HER2-positivity that is essential for the efficacy of antiHER2-targeted therapy such as trastuzumab. High proliferative activity as measured by $\mathrm{Ki}-67$ is an independent prognostic factor, but it is unclear whether this factor can predict the success of chemotherapy. If the risk of recurrence for lymph node negative patients is $20-30 \%$, chemotherapy is widely accepted as it is for all lymph node positive patients. The older type of chemotherapy, CMF, employed three types of drugs, Cyclophosphamide, Methotrexate and Fluorouracil and was shown to reduce the relative risk of breast cancer mortality by $20-25 \%$. More recent regimes employ higher doses of anthracyclines and have been shown to be more effective than CMF, with a relative reduction of $20 \%$ of the risk to die of breast cancer. However anthracyclines have been shown to be toxic for the heart and therefore the total dose of anthracyclines is strictly limited. Currently, chemotherapy employs 6 taxane-based courses followed by 3 FEC (Fluorouracil (5FU), epirubicin and cyclophosphamide) or $3 \mathrm{AC}$ (doxorubicin and cyclophosphamide) courses. Chemotherapy treatment with taxane leads to a $13 \%$ relative reduction and $1.4-2.8 \%$ absolute reduction in breast cancer mortality in comparison with the regimen without taxane. The best regimes with anthracycline and taxane are estimated to provide about $13 \%$ absolute reduction in breast cancer mortality (Bonilla et al 2010).

The biological age and general condition of the patient are both taken into account when deciding the options for treatment. Hormonal treatment is recommended for cancers with oestrogen and/or progesterone positive receptors. Tamoxifen is still the standard treatment for premenopausal women with ERpositive breast cancer and is prescribed for 5 years. In addition to the above effects the use of tamoxifen could reduce the risk of contralateral breast cancer by $38 \%$ compared with no endocrine therapy, as shown in a recent meta-analysis (Davies et al 2011). Postmenopausal women are increasingly treated with aromatase inhibitor (AI) that reduces the production of oestrogen. In the adjuvant treatment of postmenopausal ER-positive breast cancer the recommended approach is 5-year monotherapy with AI or switch therapy with 2 to 3 years of tamoxifen followed by 2-3 years of treatment with AI to a total treatment period of 5 years.

\subsubsection{Radiation therapy for breast cancer}

Adjuvant radiotherapy after surgery reduces the risk of local recurrence and increases the breast cancer specific survival after both partial mastectomy in all patients and mastectomy in patients with high risk of local recurrence. A metaanalysis of 23500 patients in 46 studies showed a relative reduction of the local relapse cases by two-thirds in five years and a $5 \%$ breast cancer specific survival benefit after 15 years (Clarke et al 2005). A more recent meta-analysis (Darby et al 2011) showed a clear reduction of the 15 year breast cancer specific mortality in women receiving adjuvant radiotherapy compared to women receiving only surgery from $25.2 \%$ to $21.4 \%$ (an absolute reduction of $3.8 \%$ ). The standard rec- 
ommended treatment for patients undergoing breast conserving surgery is postoperative radiotherapy to the remaining breast tissue. The risk of local recurrence is higher in patients younger than 40 years, for whom it is recommended to escalate the dose (give an extra dose-boost) to the surgery site (Romestaing et al 1997, Bartelink et al 2007).

The absolute gain from radiotherapy in terms of overall reduction of locoregional and distal relapses depends on the tumour size, tumour type, lymph node status, the patient's age and type of surgery (breast conserving surgery or mastectomy). In practice, radiotherapy is recommended in women operated with partial mastectomy and in women operated with mastectomy with multifocal cancers or where the tumour is larger than $50 \mathrm{~mm}$ in diameter or in women with axillary lymph nodes metastases (Regionala cancercentrum i samverkan 2014).

The "gold standard" for adjuvant radiotherapy after surgery is conventional fractionation with 50 Gy in 25 daily fractions of 2 Gy to the breast or the thoracic wall and loco-regional lymph nodes (if there is an indication for lymph node radiotherapy). A boost with external radiotherapy (16 Gy in 8 fractions of 2 Gy), but also with brachytherapy (HDR or LDR), to the site of surgery is also recommended by the Swedish national breast cancer program after breast conserving surgery, if the woman is younger than 40 years. After partial mastectomy, hypofractionation with 40 Gy in 15 fractions (Haviland et al 2013) or with 42.5 Gy in 16 fractions (Whelan et al 2010) gives comparable results in terms of local control and acute and late side effects. A meta-analysis of the studies comparing hypofractionation with conventional fractionation totalling 7095 patients showed no differences in local recurrence, overall survival, acute radiation reactions, and fibrosis or cosmetic outcomes (James et al 2010). Hypofractionation has also been adopted in 2014 by the Swedish Breast Radiotherapy Group, especially for women over 40 years of age (Blom Goldman et al 2014).

The alternative to whole breast irradiation is partial breast radiotherapy. Although the technique is not yet recommended in Sweden in the absence of a controlled clinical trial, it has been implemented in Europe and USA for low risk patients with good prognosis (Polgar et al 2010). Two large studies, comprising 4800 patients, reported more relapses in partial breast irradiation than in whole breast irradiation, $3.3 \%$ versus $1.3 \%$ in TARGIT (Vaidya et al 2010, Vaidya et al 2014) and 4.4\% versus $0.4 \%$ in ELIOT (Veronesi et al 2013). However studies are continuing to increase knowledge at long-term follow-up. 


\section{MODERN RADIATION THERAPY FOR BREAST CANCER}

The aim of radiation therapy is the local control of a malignant disease, while minimising the irradiation of normal tissues and the associated complication rates.

\subsection{Historical perspective}

The first use of radiotherapy for breast cancer took place only few years after the discovery of X-rays by Wilhelm Conrad Rontgen in 1895 and the discovery of natural radioactivity by Henri Becquerel in 1896. However, the first treatments were associated with many skin reactions caused by the poorly penetrating Xrays available at the time (Jassem 1998). Increased availability of deeply penetrating radiation led to a decrease of the complication rates and the subsequent establishment of radiation therapy as an effective treatment modality for breast cancer in the 1940s. The continuous parallel development of megavoltage radiotherapy, radiation dosimetry, image-based treatment planning and irradiation techniques have gradually improved the results of breast cancer radiotherapy.

\subsection{Radiotherapy techniques}

The current standard of care for breast cancer radiotherapy is threedimensional conformal radiotherapy. Dose planning is performed on computed tomography images acquired in supine position with 2 or $3 \mathrm{~mm}$ slice thickness, usually with 4-6 MV photons, but higher energies are also used for compensating fields or for patients with larger breast. The irradiation of the breast is usually achieved with tangential, isocentric radiation fields and compensating fields are used when individually needed. The irradiation of the regional lymph nodes is achieved with anteroposterior radiation fields, using a common isocenter with the tangential breast fields. High photon energy is most often used for the posterior field and low energy for the anterior field. All radiation fields are adapted to the PTV and the organs at risk with appropriate choice of gantry angle, collimator angle and opening of the MLC. Dynamic wedges could also be used to improve dose uniformity in the target. Irradiation of the tumour bed (boost) is achieved with one or two photon fields, electron fields or brachytherapy depending on the location. These treatment techniques ensure a clinically relevant treatment benefit with lower levels of risk of side effects compared with historically used techniques. 
Other techniques have been proposed to further increase dose uniformity in the target and they include the use of forward and inverse planning intensity modulated radiotherapy (IMRT) as well as particle therapy (Johansson et al 2002a, Lomax et al 2003, Bjork-Eriksson and Glimelius 2005, Fournier-Bidozet al 2009). Forward planning IMRT (sometimes called simplified IMRT) implies the use of dynamic MLC to produce intensity-modulated fields to compensate for the external shape of the breast and improve the dose distribution in the target as well as sparing of critical organs. Inverse planning IMRT calculates a mathematical optimum for the coverage of the target and the normal tissue constraints. However, the optimum dose distribution in the target and the normal tissues from inverse planning IMRT is quite sensitive to motion and setup uncertainties due to the steep dose gradients. Furthermore, some studies have questioned the clinical advantage of inverse planning IMRT over simplified IMRT or that of IMRT in general over conventional techniques for breast cancer (Kestin et al 2000, Chui et al 2002, James et al 2004).

Proton therapy has also been considered for the treatment of breast cancer, as it allows more favourable dose distribution due to the limited range of these particles in tissue, the relatively low entrance dose and the existence of the Bragg peak where the maximal dose of the beam is deposited relatively deeply in tissue. The potential of protons for breast radiotherapy has been explored in dose planning and clinical studies employing both passively scattered proton fields and actively scanned beams (Kozak et al 2006, Bush et al 2007, Ares et al 2010, MacDonald et al 2013). Although more expensive, the latter technique has the advantage of allowing further modulation of the beam and reducing the neutron contamination in comparison with passively scattered beams. Concerns have also been raised with respect of the sensitivity of this technique to motion and setup uncertainty (ICRU 2007), but these were shown to have small impact in the case of the treatment for breast cancer (Ares et al 2010). The proton scanning technique is now available at the Skandion Clinic, the national proton radiotherapy centre in Sweden, and therefore the potential of the technique for breast cancer radiotherapy has to be investigated before its clinical implementation.

\subsection{Definition of target volume for breast can- cer radiotherapy}

The comparison of treatment approaches employed in different centres requires the standardisation of the ways radiation dose is prescribed, recorded and reported. The International Commission on Radiation Units and Measurements (ICRU) has issued several sets of recommendations to be used in the treatmentplanning and reporting processes for several treatment modalities: ICRU Report 50 (1993), ICRU Report 62 (1999), ICRU Report 71 (2004), ICRU Report 78 (2007) and ICRU Report 83 (2010). These reports standardise prescribing, recording and reporting of photon, electron and proton beam radiotherapy. They 
make use of volumes related to both tumour and normal tissues that are defined to facilitate treatment planning and reporting. The gross tumour volume (GTV) is the volume of known tumour being defined as the gross demonstrable extent and location of a primary tumour or other tumour mass, including localisation in all radiological diagnostics. The clinical target volume (CTV) represents the known tumour volume and the suspected microscopic tumour infiltration outside the primary GTV. An adaptation of these concepts is used for breast cancer radiotherapy, taking into account the adjuvant delivery of radiation therapy for this disease. For breast cancer radiotherapy the CTV is all breast tissue and pectoral fascia and for loco-regional treatment the ipsilateral axillary and supraclavicular nodes are added. For post-mastectomy patients the CTV is the chest wall corresponding to the previous extent of the breast. ICRU Report 62 (1999) introduced a new volume, the internal target volume (ITV), which accounts for the expected physiological movements and other physiological variations of the CTV. In contrast with these anatomically or physiologically-based volumes, the planning target volume (PTV) has been defined as a geometrical concept for treatment planning and evaluation to ensure that the planning constraints are met. In general, the PTV is obtained from the CTV by adding a $5-10 \mathrm{~mm}$ margin to account for internal motion and for setup uncertainties. A clinical target volume of the tumour bed (CTV-T) could also be defined as the original location of the tumour bed, after the primary tumour is removed through surgery, with proper margin. The corresponding planning target volume of the tumour bed (PTV-T) is constructed by adding a $5-10 \mathrm{~mm}$ margin from the CVT-T. Similarly, volumes of organs at risk (OAR) and planned risk volumes (PRV) are used in treatment planning and evaluation of the dose constraints to the irradiated normal tissues.

The current standard of care according to the Swedish national recommendations does not include the internal mammary lymph nodes (IMN). A randomized EORTC trial studied the impact of radiation therapy to the IMN and also to the medial supraclavicular lymph nodes (Poortmans et al 2001). The ten-year results from this study showed significantly improved disease-free survival, but not significantly improved overall survival (Poortmans et al 2015). A recently published randomized study on 1334 patients has not shown a clear benefit from including the internal mammary nodes in the radiotherapy target (Hennequin et al 2013).

\subsection{Side effects in breast cancer radiotherapy and relevant organs at risk}

The treatment-related irradiation of normal tissues can lead to acute and late side effects that reduce the quality of life of the patients and could even be lifethreatening. Acute toxicity appears during or up to about six months after radiotherapy is finished and usually disappears without permanent damage, although some studies showed that it may also modulate the late effects in the same tissue (Dorr and Hendry 2001). Late complications appear long time after the comple- 
tion of radiotherapy (six months or even later) and consequently are more serious as only symptom relief is available in many cases.

The risk of complications in irradiated normal tissues is usually quantified as normal tissue complication probability (NTCP) which could be related to the radiation dose and the irradiated volume of the normal tissue (Bentzen et al 2010). Furthermore, the severity of complication depends on the irradiated volume, total dose and fractionation to the involved structures, defined as organs at risk (OAR), and radiation type. Several criteria are available for the assessment and classification of normal tissue damage such as those of the Late Effects of Normal Tissues (LENT) Consensus Conference (LENT 1995) or of the Radiation Therapy Oncology Group (RTOG) and the European Organization for Research and Treatment of Cancer (EORTC) (Cox et al 1995).

The first systematic evaluation of normal tissue tolerance in relation to radiation doses has been performed by Emami and co-workers (Emami et al 1991) and has been used for many years for treatment plan evaluation in radiotherapy. The QUANTEC (Quantitative Analysis of Normal Tissue Effects in the Clinic) collaboration (Bentzen et al 2010) has produced the latest updated overview of dose and volume constraints. These recommendations have been accounted for in the development of the recommendations in the national care program for breast cancer (Regionala cancercentrum i samverkan 2014, Blom Goldman et al 2014), in order to minimise the side effects after breast cancer radiotherapy. These recommendations are used for dose and volume constraints, but radiotherapy plans in clinical practice are in the end the result of individualised planning in which the strong constraints are used together with plan-tailored optimisation constraints in order to achieve a clinically acceptable dose distribution. For example, hard constraints are used for the CTV-T dose coverage and for the multifocal or lobular disease PTV while softer constraints are set for the heart and the lung as organs at risk.

In breast cancer radiotherapy, acute toxicity includes redness of the skin, oedema of the breast and radiation-induced pneumonitis that may appear 1-3 months after completion of radiation therapy (Lind et al 2001). Late toxicity includes radiation induced cardiovascular disease that results from injury to the heart and the blood vessels with microangiopathy - destruction of the microvascular network of the myocardium, leading to ischaemia of myocytes and replacement by fibrosis (Fajardo and Stewart 1973), macroangiopathy - increased depletion of media smooth muscle cells and more extensive fibrotic changes in the media in comparison to non-irradiation coronary artery disease (Brosius et al 1981) and atherosclerosis (Schultz-Hector and Trott 2007). Increasing importance has been given to the late effects associated with the irradiation of the left anterior descending (LAD) artery (Nilsson 2012).

The early randomised radiotherapy trials and the EBCTCG meta-analyses showed a decrease in breast cancer deaths that was counterbalanced by an increase in cardiovascular mortality (Cuzick et al 1994). In addition, left-sided 
breast cancer has been associated with a higher mortality due to ischaemic heart disease (IHD), compared to right-sided disease (Paszat et al 1998, Darby et al 2005, Roychoudhuri et al 2007). Cardiovascular complications could appear months to years after the treatment and their full characterisation would therefore require quite long follow-up. Cardiotoxic effects could also be caused or modulated by the chemotherapy regime with anthracyclines or trastuzumab. Anthracycline induced cardiotoxicity depends on the medication and the cumulative dose (for doxorubicin the rate varies from $4 \%$ to more than $36 \%$ for patients receiving $500-550 \mathrm{mg} / \mathrm{m}^{2}$ ). Cardiotoxicity could be either early-onset chronic progressive, within the first year after treatment, or late-onset chronic progressive, presenting as dilated cardiomyopathy from 1 until 30 years after treatment (one hypothesised mechanism for causing it is the apoptosis of the myocardial cells). Cardiac toxicity from trastuzumab is frequent but almost always reversible when the drug is stopped. In comparison, epirubicin and liposomal doxorubicin showed reduced cardiotoxicity (Bovelli et al 2010). The national care program for breast cancer recommends regular clinical control of cardiac function (LVEF) with echocardiography combined with the recording of resting electrocardiogram, which should be performed before the initiation of treatment with trastuzumab and then every 3 months during treatment (Regionala cancercentrum i samverkan 2014). Given the complexity of the problem, increased attention has been paid to the possibility of early monitoring cardiotoxicity (Marwick and Narula 2014, Kongbundansuk and Hundley 2014).

Given the relative frequency of the acute and late side effects, the lungs, the heart and the LAD are the main OAR considered in relation to breast radiotherapy. Radiotherapy of the axilla could also increase the risk of arm lymphedema leading to impaired shoulder mobility, but this side effect is rare with modern treatment techniques (Swedborg and Wallgren 1981). Hypofractionation has also been shown to increase the damage to the brachial plexus (Johansson et al 2002b). Other organs like the spinal cord, oesophagus, trachea or the thyroid gland are in close proximity to the target of radiotherapy for breast cancer. Fortunately, radiation damage to these organs is rarely diagnosed nowadays.

In the context of late effects of breast radiotherapy, it is important to consider the results of a meta-analysis showing that the breast cancer specific survival gain was $5.4 \%$ after 15 years, while the total survival gain was $4.4 \%$ for the group with locoregional radiotherapy after mastectomy (Clarke et al 2005). The difference between these is attributed mainly to the increased risk of cardiovascular mortality (the ratios of annual event rates of mortality before recurrence, irradiated versus unirradiated were $1.25 \pm 0.06$ for heart disease, $1.27 \pm 0.07$ for stroke and $1.12 \pm 0.12$ for circulatory disease), and also to a low but significantly increased risk of lung cancer. This latter aspect highlights the increasing importance of radiotherapy induced secondary cancers (Dasu and Toma-Dasu 2014) in the light of the favourable prognosis of breast cancer patients. 


\subsection{Pathogenesis and histopathology of radia- tion-induced heart and coronary artery damage}

Radiation-induced cardiovascular toxicity could be grouped in several categories based on the underlying mechanisms for damage. Thus, cardiovascular toxicity could be caused by direct injury to the cardiac myocytes, provocation of myocardial fibrosis, endothelial dysfunction and vascular injury, induction of myocarditis, pericarditis, conduction abnormalities and valvular disease or the exacerbation of existing cardiovascular risk factors (Kongbundansuk and Hundley 2014). All these mechanisms lead to reduced pumping function of the heart which can eventually lead to congestive heart failure when the needs of the body are no longer met. It is important to recognise that both radiation and other adjuvant treatments act as cardiotoxic agents and could initiate these reactions. Furthermore, the effects are modulated by other promoting agents that do not directly have a cardiotoxic influence. Thus, radiation combined with excess lowdensity lipoprotein enhances the risk of atherosclerotic development which could lead to ischemic heart disease, both stable and unstable angina and myocardial infarction. Hormone deprivation therapies have also been associated with subsequent cardiovascular events (Ewer and Gluck 2009, Amir et al 2011).

Pericardial disease can appear under the first year after radiotherapy and can persist for several years as a constrictive process without clinical symptoms. Major heart complications appear several years after radiation treatment (Hooning et al 2007, McGale et al 2011). As these manifestations appear when the damage to the tissue can no longer be reversed it is quite important to detect cardiac damage early and if possible initiate appropriate preventive strategies to reduce the risk of serious and permanent damage to the cardiovascular system.

\subsection{Monitoring cardiac side effects}

Several methods are available for investigating cardiac function as well as for monitoring radiation-induced damage. A simple and well-known technique is the electrocardiogram (ECG) which shows the electrical activity of the heart. While it is the oldest and most established of all methods, it has too low sensitivity to reliably detect early cardiac dysfunctions (DeVita et al 2014).

Echocardiography is widely used for hemodynamic assessment of patients pre- and postsurgery as well as in sepsis and trauma and is well suited for assessing cardiac function after treatment for malignancies (Tzonevska et al 2011). It offers real-time information on systolic, diastolic and valvular function, as well as hints to possible complications such as pericardial effusion. It can easily quantify the strain, i.e., the relative length change of the myocardium, in the different segments of the heart. Due to its sensitivity to detect minute changes, the method is quite attractive to characterise the early stages of cardiac dysfunction during and after treatment in patients who receive radiation treatment for left-sided 
breast cancer, although it does not offer insights into the mechanism of this cardiac damage.

Cardiovascular magnetic resonance $(\mathrm{CMR})$ is another imaging modality that evaluates cardiac morphology and function with high temporal and spatial resolution. In addition it has the unique capability for characterisation of tissue and has recently been recommended as a suitable method to identify cardiovascular toxicity after cancer treatment (Hundley et al 2010). It could be used to visualise oedema, but also to quantify parameters important for systolic heart failure such as the ejection fraction (EF), i.e., the fraction of outbound blood pumped from the heart with each heartbeat, as well as cardiac strain.

\subsection{Tolerance levels and recommendations for the heart}

The relationship between irradiation of the breast and cardiac mortality has been documented in several previous studies (Gagliardi et al 1996, Gagliardi et al 2010). Thus, it has been shown that the risk for cardiac complications was greater when the left breast was irradiated compared to the right breast and this correlated with the mean dose to the heart (6.3 Gy versus 2.7 Gy). For doses to the heart above 30 Gy the risk of radiation-induced heart disease increases in a relatively short time interval of a year or two, but for lower doses the latency period is a decade or even longer. More recent studies showed significant changes in myocardial systolic strain in breast cancer patients that have received doses as low as 3 Gy (Erven et al 2013). The risk of major coronary complications (myocardial infarction, coronary revascularization) or death from ischemic heart disease was better correlated with the mean dose to the heart than with the mean dose to the left anterior descending coronary artery. Rates of major coronary events increased linearly with the mean dose to the heart by $7.4 \% \mathrm{~Gy}^{-1}(95 \%$ confidence interval 2.9-14.5\%; $\mathrm{P}<0.001)$ starting few years after radiotherapy and continuing during a follow-up of 20 years and were similar in women without and with cardiac risk factors. The mean dose to the heart in the study was 4.9 Gy corresponding to an equivalent dose in 2 Gy fractions of 3.9 Gy. It should however be pointed out that the heart doses in this study have been derived from dose reconstructions calculated using the pencil beam convolution algorithm (Darby et al 2013, Taylor et al 2009, Taylor et al 2011).

These observations were the basis for the clinical recommendations from QUANTEC (Gagliardi et al 2010). The Swedish radiotherapy group had proposed a similar regime and recommended that the average dose to the heart should be less than $10 \%$ (preferably below 4\%) for a prescribed dose of $50 \mathrm{~Gy}$ in 25 fractions and that the maximal heart distance included in the tangential fields should be less than $1 \mathrm{~cm}$ with the highest constraints for dose coverage of the 
CTV-T and for multifocal or lobular disease of the PTV (Blom Goldman et al 2014).

\subsection{Pathogenesis and histopathology of radia- tion-induced damage to the lung}

The most common complication from the irradiation of the lung is radiation pneumonitis, an inflammatory reaction of lung tissue, ranging from asymptomatic pneumonitis detected on radiological images to life-threatening pneumonitis that could lead to respiratory failure (Brown et al 2015). Symptomatic pneumonitis requiring medical intervention is quite rare nowadays appearing in only $1-2 \%$ of the patients undergoing radiotherapy because of breast cancer. The symptoms from radiation-induced lung damage usually occur within 9 months after the conclusion of radiotherapy. The symptoms are cough, fever and shortness of breath, but can also include frothy sputum and pleurisy (Chung et al 2012). The early radiation-induced pneumonitis is caused by damage to the septal capillary bed and the lung alveoli. The most important mechanism for such complications is the ablation of type II alveolar cells that leads to early surfactant release into the alveoli. This can happen quite quickly after radiotherapy without clinical or radiological manifestations. One to three months after treatment the loss of alveolar cells type II becomes clinically observable. This leads to the second phase of the development of injury characterised by the proliferation of alveolar type II and compensatory hypertrophy of lamellar bodies. The late fibrotic phase starts 3-6 months after radiotherapy and is characterised by sclerosis of the alveolar wall, extensive endothelial damage, loss of capillaries and appearance of fibrosis with loss of function (Perez and Brady 1997).

\subsection{Monitoring lung damage}

Clinical symptoms of lung damage are presently rare, but $25 \%$ of patients can have transient cough for a few months after the end of treatment. In case these symptoms are also associated with fever and shortness of breath, treatment with corticosteroids is recommended, which can rapidly clear symptoms after one or two days. After recovery, fibrosis can still be evident on chest radiographs, and a reduction of vital capacity and diffusion capacity is seen on spirometry, usually without clinical symptoms (Jassem 1998). For measurement and evaluation of lung function, spirometric measurements of vital capacity, FEV1s values (the forced expiratory volume in 1 second) and DLCO (diffusing capacity of carbon monoxide reflecting lung membrane function) is standard. Later monitoring of lung damage is recommended at 4 months after radiotherapy, using CT and the modified Arriagada classification (Arriagada et al 1989). Here, the lung volume is divided into the apical-lateral, central-parahilar and basal-lateral regions. Increases in lungs density observed on CT are graded (0-no change, 1-low 
opacity, 2-moderate opacity, 3-complete opacity) and the highest densities of each region are scored. A total score 1-3 shows mild radiological tissue reaction, but scores 4-9 represent moderate to severe reaction. Spirometry is recommended after 6, 12 and 24 months and may show reduced DLCO and FEV1 value, which may partially return to pre-treatment values after 12 months.

\subsection{Tolerance levels and recommendations for the lung}

To avoid symptomatic pneumonitis QUANTEC recommends that the volume of lung receiving doses above $20 \mathrm{~Gy}\left(\mathrm{~V}_{20 \mathrm{~Gy}}\right)$ should be below $30 \%$ of the total volume to keep the risk of side effects below 20\%. The mean lung dose should be below 7 Gy to keep the risk below 5\% and below 13 Gy to keep the risk below 10\% (Marks et al 2010).

The Swedish national breast cancer program recommends for breast cancer radiotherapy that the following optimisation criteria be used for the lung: the volume of the ipsilateral lung receiving more than $40 \%$ of the prescribed dose should be lower than $20 \%$ of the lung volume and that the average dose to the ipsilateral lung should be less than $20 \%$ of the prescribed dose for breast irradiation only. In case of locoregional irradiation where the target volume is greater, the volume of the ipsilateral lung receiving more than $40 \%$ of the prescribed dose should be lower than $35 \%$ of the lung volume and the average dose to the ipsilateral lung should be less than $40 \%$ of the prescribed dose (Blom Goldman et al 2014). 


\section{AIMS}

This project aimed at characterising the radiation burden to normal tissues from modern radiotherapy techniques that could lead to untoward effects and to identify practical ways to minimise their irradiation. This was achieved through several studies dedicated to specific issues in breast cancer radiotherapy.

Study 1 aimed to investigate the clinical implications of using the Analytical Anisotropic Algorithm (AAA) for dose calculations in breast cancer radiation therapy.

Study 2 aimed to investigate the potential of the irregular surface compensator (ISC) technique to improve target coverage in breast cancer radiotherapy in comparison to three-dimensional conformal radiotherapy (3D-CRT).

Study 3 aimed to investigate the feasibility of scanned proton beams to reduce cardiopulmonary radiation burden in adjuvant radiation therapy for breast cancer.

Study 4 aimed to investigate the additional benefit of proton radiation therapy for breast cancer with and without respiratory gating in comparison with photon radiotherapy.

Study 5 aimed to investigate the impact of physiological breathing motion for breast cancer radiotherapy with proton beam scanning. 


\section{MATERIAL AND METHODS}

\subsection{Patient cohorts}

The individual studies that are part of this thesis required the collection of suitable patient cohorts. In this work, the cohorts were selected based on available patient numbers and from clinical experience of the standard methods. We did not have the resources or it was not deemed feasible to recruit patients in a multicenter setting to allow for larger cohorts. Thus, for the first study, the patient cohort included 40 consecutive patients who were previously treated with standard three-dimensional conformal radiotherapy for left-sided breast cancer. The patient cohort was divided into two sub-groups, one who received treatment to the breast only (WBO) and another where treatment was given to the locoregional lymph nodes (BSC) as well. The cohort was representative for ordinary clinical practice and reflected the inter-patient heterogeneity seen in practice.

In contrast, studies II and III were based on a smaller group of ten patients for which the standard three-dimensional conformal radiotherapy technique had difficulties in achieving the target coverage and radiation burden to the organs at risk according to national recommendations. The aim was to investigate whether simplified IMRT (study II) or proton therapy (study III) could improve target coverage without compromising cardio-pulmonary sparing. Such an approach is indeed needed for the analysis of the potential for improvement of advanced radiotherapy techniques in particularly difficult cases, as modern-day conventional techniques have considerably reduced radiation burden and complication rates in the general breast cancer population (Brown et al 2015).

The patient cohort for the fourth study included twenty patients selected from a larger group originally treated with photon radiotherapy under enhanced inspiration gating (EIG) at the Oncology Department at Lund University Hospital, which has the longest EIG experience in Sweden. Ten of the patients in this cohort had only breast treatment and ten received treatment to the breast and the loco-regional lymph nodes. Each subgroup was further divided into 5 cases with best and 5 cases with worst LAD sparing with the EIG technique.

The patient cohort for study $\mathrm{V}$ included twelve thoracic patients who had CT datasets acquired during breath-hold at inhalation, breath-hold at exhalation and in free-breathing mode. The multiple CT datasets for each patient allowed the study of the impact of respiratory motion on the radiotherapy with scanned proton beams, by studying the changes in dose distributions to the target and the organs at risk when varying the breathing phase used for planning and recalculating the plans for the other breathing phases. 
The use of data from previously treated radiotherapy patients has been approved by the regional ethical review boards in Linköping (2013/377-31, 2014/505-31) and Lund (2013/742).

\subsection{Calculation algorithms in photon therapy}

Treatment planning systems are used in modern radiation therapy to calculate dose distributions taking into account the CT-based three dimensional representations of individual patients. The dose calculation algorithm is a central component of the treatment planning system being responsible for the calculation of the number of monitor units required for the treatment, as well as for the calculation of the dose distributions in the patient. Several algorithms are now available in commercial treatment planning systems with various degrees of accuracy in modelling the scattered radiation and the effects of heterogeneities in the patient (Knoos et al 2006). For the Eclipse treatment planning system (Varian, Palo Alto, CA, USA), the most commonly used algorithms for photon therapy are the pencil beam convolution (PBC) algorithm and the anisotropic analytical algorithm (AAA), that are the objects of one study in this thesis (Paper I). The PBC algorithm calculates the dose as a convolution of the energy fluence of the primary beam with a pencil kernel describing the dose deposition of a narrow photon beam in water, using corrections for heterogeneities along fan lines (Storchi et al 1996, Storchi et al 1999). It provides a good compromise between calculation accuracy and speed in homogeneous media. The AAA is a more advanced algorithm that better takes into account the lateral energy transport, providing improved dose calculation accuracy for heterogeneous media (Ulmer et al 2005, Van Esch et al 2006). More advanced algorithms based on solving the radiation transport equations or even on full Monte Carlo modelling are also available but not discussed here.

Although the AAA has been shown in several studies to provide improved dose accuracy in comparison to the PBC (Van Esch et al 2006, Bragg et al 2006), it has only slowly been adopted in clinical practice, partly because the main part of clinical knowledge regarding normal tissue tolerances has been built on PBCcalculations, as is for example the case of the QUANTEC recommendations for the lung (Marks et al 2010) and for the heart (Gagliardi et al 2010). The implications of this algorithm for clinical practice have been investigated in Paper I in this thesis.

\subsection{Irregular surface compensator (ISC)}

Radiation therapy for breast cancer is performed to a part of the body characterised by rounded body contours, where conformal radiotherapy with multi-leaf collimators (MLC), dynamic wedges and compensating fields might not always lead to good target uniformity and significant dose sparing of the normal tissues. 
In these cases, more advanced planning techniques would be required to improve the dose distributions in the target and the organs at risk. One such technique is forward planning with electronic compensation that takes into account the curvature of the body contours to provide homogenous dose to the target (Chui et al 2002, Caudell et al 2007, Emmens and James 2010, Hideki et al 2013). The method uses dynamic MLC to modulate individual beamlets across the photon fields to improve dose distributions. The irregular surface compensator (ISC) is the implementation of an electronic compensation algorithm in the Eclipse treatment planning system and is the subject of one study in this thesis (Paper II). ISC is thought to provide improved dose distributions that are comparable with those that could be achieved through inverse planning intensity modulated radiation therapy (IMRT), at the same time being less resource-demanding or sensitive to the interplay effects caused by motion and setup uncertainties as the latter method (Caudell et al 2007, Hideki et al 2013). Most studies regarding the performance of electronic compensation methods date from before the introduction of convolution-superposition algorithms for dose calculation.

\subsection{Proton therapy}

Proton radiation therapy is a new treatment option for breast cancer patients in comparison to photon therapy. It is expected to further improve the outcome through favourable dose distributions (Bjork-Eriksson and Glimelius 2005, Weber et al 2006). Thus, protons penetrating matter have a finite range given by their energy and the medium through which they travel. As they enter a medium, they deposit little energy until they are about to stop, when they deposit most of their energy in a Bragg peak with a steep dose falloff beyond which there is virtually zero dose deposition.

Proton therapy could be delivered either with passively scattered beams or with actively scanned pencil beams (Suit et al 2010). Passive scattering involves the use of scattering and range-shifting materials to spread a proton pencil beam laterally and in depth to create a uniform dose distribution that could be employed for treatment though the use of field-specific apertures and range compensators. The spread in depth of the protons usually aims at the formation of a spread-out Bragg peak (SOBP) that ensures a uniformly high dose over a certain depth interval.

Active scanning involves the use of magnetic fields to scan the beam in the transversal direction, while energy modulation is used for depth scanning, offering the possibility to create uniform SOBPs as well as more complex dose distributions suitable for intensity modulated proton therapy (IMPT). Active beam scanning is expected to provide better dose conformity, while minimising the use of beamline-, patient- or field-specific hardware. Additionally, IMPT also provides an advantage from a radiation protection point of view by decreasing the production of neutrons and activation products in the beam line. 
Protons also have an increased radiobiological effectiveness compared to high energy photons. Most experiments performed in the middle of a SOBP suggested that the relative biological effectiveness (RBE) of the protons is about 1.1 and this led ICRU to recommend the use of this generic value for the uniform scaling of all proton dose distributions (ICRU 2007). Nevertheless, experimental data show a variation of the RBE of protons with tissue type, investigated endpoint, dose and energy of the protons (Gerweck and Kozin 1999, ICRU 2007). It is particularly noteworthy that the increase in proton stopping power in the distal part of the Bragg peak is associated with an increase in RBE faster than the dose falloff, yielding a tissue-dependent increase in the range of the RBE-weighted absorbed dose that has to be accounted for in treatment planning. More efforts have been done lately to quantify this feature and include it in radiobiological models (Carabe et al 2012, Dasu and Toma-Dasu 2013, Wedenberg et al 2013) to be used for the advanced optimisation of proton plans (Wedenberg and TomaDasu 2014).

In spite of the mentioned advantages, proton therapy has scarcely been used in comparison to photon therapy as it is still expensive (Lundkvist et al 2005) and also susceptible to range and setup uncertainties and in the case of scanned beams to interplay effects caused by interferences with physiological motion (ICRU 2007). Proton beam scanning is available in Sweden at the Skandion Clinic, the national proton therapy centre in Uppsala, which has started clinical operation on the $31^{\text {st }}$ of August 2015. The potential of protons for breast cancer radiation therapy has been investigated in three studies that are part of this thesis (Papers III, IV and V). Two planning techniques have been explored, single field uniform dose (SFUD) which aims at delivering uniform doses to the target from each field and IMPT where the contribution of all fields in the plan is simultaneously optimized to deliver a uniform dose to the target.

\subsection{Respiratory gating}

Respiratory movement has long been a cause of concern for thoracic radiotherapy as it could change the relative position of the target, normal tissues and the radiation beam (Langen and Jones 2001). This could result in a worst case scenario in missing the target with the high dose region or misplacing the normal tissues into the high dose region. The concerns are further enhanced if more advanced modalities like IMRT or proton therapy are used to create complex dose distributions for treatment. Studying the effect of respiratory movement on dose distributions in radiation therapy, Willet and co-workers observed that some phases of the breathing cycle could offer both a stable position of the structures involved and a good separation of the target and normal tissues leading to a significant sparing of the latter (Willett et al 1987). They consequently proposed the use of respiratory gated radiotherapy to limit motion during irradiation and to achieve more favourable dose distributions. The term is now used for a variety of 
techniques, including deep inspiration breath hold (DIBH) where the patient takes a deep inspiration and then holds breath for a relatively long time and enhanced inspiration gating (EIG) where the patient is coached into breathing with larger amplitudes, but no attempt is made to hold breath for a longer time interval. Clinical implementation of the technique requires real-time management of the breathing cycle of the patients as well as control systems that allow turning on or off the imaging or the irradiation systems used, based on the measured respiratory amplitude.

Studies on the use of respiratory gating for breast radiotherapy with photons have shown that doses to the OARs could be reduced (Korreman et al 2006, Vikstrom et al 2011, Hjelstuen et al 2012) and this would eventually be translated into a reduction of the radiotherapy-induced complications for these patients (Shah et al 2014). Investigating the potential of the technique for proton therapy was the subject of one study in this thesis (Paper IV) as few studies have investigated this aspect of proton therapy (Mast et al 2014, Lin et al 2015). The more general impact of the breathing motion on dose distributions from proton radiotherapy has been addressed in another study in this thesis (Paper V). 


\section{RESULTS}

\subsection{Paper I}

Paper I showed significant differences of the dose distributions between the plans calculated with AAA and with PBC for both target and OAR. The analysis was performed separately for patients receiving breast treatment only and for those receiving treatment to the breast and the loco-regional lymph nodes. For the latter group the largest difference was for PTV and CTV-T coverage according to the AAA calculations which extended the 93 and $95 \%$ isodoses into the PTV. All AAA plans showed significantly larger heterogeneity index for the PTV. Local increases in dose, "dose hotspots", were sometimes observed near sensitive structures like nerves of the brachial plexus. AAA plans also showed different dose distributions in the ipsilateral lung, with higher volumes receiving doses below 25-30 Gy ( $\mathrm{V}_{10}$ Gy was significantly larger in AAA plans), but smaller volume receiving doses above $30 \mathrm{~Gy}$. Another important finding was that AAA predicted significantly lower doses to the heart.

\subsection{Paper II}

The Irregular Surface Compensator technique (which could be regarded as an intermediate step between IMRT and conventional RT with static fields) had some potential for improving dose distributions in comparison with standard three-dimensional conformal radiotherapy for breast RT. With ISC, PTV and CTV-T achieved a better coverage manifested in the reduction of hotspots and a smaller heterogeneity index. There was also a reduction of the doses to the ipsilateral lung, the LAD and the heart for patients with disease of the left-side, but the differences did not reach statistical significance. The technique could have further advantages for patients with larger PTV, reducing the risk for complications such as fibrosis of the skin and the lung.

\subsection{Paper III}

Proton therapy with scanned pencil beams improves target coverage and spares OAR compared with therapy with standard photon irradiation with ISC. Both planning approaches for protons reduced hotspots and the heterogeneity index for the PTV, as well as the doses to the heart and the LAD. Unfortunately the dose to the contralateral breast increased, but was quite low in absolute terms and will not influence the potential future treatment of the contralateral breast. Proton treatment may also reduce the integral dose outside PTV, from $67 \mathrm{~Gy} \cdot \mathrm{kg}$ 
to $48 \mathrm{~Gy}(\mathrm{RBE}) \cdot \mathrm{kg}$ for both SFUD and IMPT. The most important finding was however the significant reduction of the mean heart dose, from 2.2 Gy to $0.4 \mathrm{~Gy}$ (RBE), and the dose to the LAD. Proton irradiation also showed a trend towards increased low-dose component in the ipsilateral lung.

\subsection{Paper IV}

This study separately analysed proton and photon plans for enhanced inspiration gating, compared with treatment under free breathing. Regardless of the respiratory pattern, proton plans were better for all patients. The heterogeneity index decreased from $12 \%$ to $5 \%$ with protons. The mean LAD doses were significantly lower for proton plans and the mean dose to the heart decreased by a factor of 4 in WBO patients and by a factor of 10 in BRN patients. A reduction of the mean dose to the ipsilateral lung was also observed, in BRN patients from $12 \mathrm{~Gy}$ in EIG and 14 Gy in FB in photon plans to 7 Gy (RBE) in EIG and respectively 6-7 Gy (RBE) in FB in proton plans. In comparison, for the WBO group the mean dose to the ipsilateral lung was 5-6 Gy (RBE) with proton therapy which was not significantly different from that of photon plans. For the WBO patients, the volume of the lung receiving doses above $10 \mathrm{~Gy}(\mathrm{RBE})\left(\mathrm{V}_{10 \mathrm{~Gy}}\right)$ increased with protons from $12 \%$ to $19 \%$ in FB and from $13 \%$ to $23 \%$ in EIG. $\mathrm{V}_{10 \text { Gy }}$ for the lung was higher in EIG proton plans than in FB proton plans. As in the previous study the integral dose was reduced for all patients from $76-80 \mathrm{~Gy} \cdot \mathrm{kg}$ with photons to an average of 51-52 Gy (RBE) $\cdot \mathrm{kg}$ with protons.

\subsection{Paper V}

This study showed that breathing motion can reduce target coverage for proton beam scanning. Inhalation increased the ipsilateral lung burden [average dose 5.8-6.8 Gy (RBE)], but exhalation decreased it [average dose 3.1-4.5 Gy (RBE)]. The volume of the ipsilateral lung receiving doses above 20 Gy (RBE) varied from $4-6 \%$ at exhalation to $11-13 \%$ at inhalation. Only small changes were observed for the doses to the LAD and the heart parameters during the breathing cycle. The largest differences were observed for IMPT plans, but the changes were very small and likely without observable clinical implications. All these results suggest that breathing motion might have little impact for the chosen beam arrangements with scanned proton beams. 


\section{GENERAL DISCUSSION}

The addition of radiation therapy as adjuvant treatment for patients with breast cancer improved local control and overall survival (Clarke et al 2005, Darby et al 2011, Brown et al 2015). The rather long life expectancy for this group of patients highlights the importance of limiting the risk for normal tissue complications to maintain the quality of life for these patients. Indeed, there is a risk that normal tissue morbidity may offset the potential benefit that radiotherapy brings for breast cancer patients. In this respect, the present project has been dedicated to the study of the radiation burden to normal tissues from modern radiation therapy techniques and the ways by which these and the associated complications could be reduced. Various aspects of this problem have been investigated, from the importance of the calculation algorithm used to characterise the dose distributions in the tumour and normal tissues (Paper I) and the potential of new irradiation techniques (Paper II and III) to the impact of breathing motion on the dose distributions from advanced treatment modalities (Paper V) and the additional benefit of systems that could be used clinically to limit the irradiation of normal tissues (Paper IV).

Dose distributions in radiation therapy are calculated by treatment planning systems (TPS) using algorithms with various degrees of complexity. Pencil beam convolution algorithms are among the oldest photon algorithms employed that provide a satisfactory degree of accuracy in homogeneous media. Therefore, most of the clinical experience regarding the correlations between complication rates and radiation burden in normal tissues comes from dose calculations with these algorithms, including many national and international tolerance levels and dose recommendations like those of Emami et al (1991) or those of the QUANTEC collaboration (Bentzen et al 2010). More recent algorithms like AAA predict better and more realistic dose distributions, especially in heterogeneous media (Bragg and Conway 2006, Van Esch et al 2006) and therefore are recommended for breast radiotherapy. However, it has been shown that changing the algorithm for dose calculations from $\mathrm{PBC}$ to AAA influences the evaluation of parameters for the risk of complications in normal tissues (Bufacchi et al 2013, Hedin and Back 2013, Petillion et al 2014) and in consequence influences also the dose thresholds that are associated with certain levels of complications. Knowledge on the differences in predictions between algorithms could be obtained in studies comparing their performance in patients. It should be noted that many previous comparative studies used a limited number of patients with mainly tangential irradiation of the breast, e.g., a single patient in Knoos et al (2006) or ten patients in Basran et al (2010). Only in recent years the number of patients was increased in several parallel studies, e.g., twenty in Yoo et al (2012), Bufac- 
chi et al (2013) and Hedin and Back (2013) and 30 in Petillion et al (2014). To the best of the knowledge, Paper I used the largest patient cohort this far (40 patients) to study the differences between AAA and PBC predictions. The cohort included patients with both WBO and BSC irradiations, which ensured a representative cross-section of patients from current clinical practice. The results of Paper I predicted increased heterogeneity in the target volume and higher doses to the ipsilateral lung, in agreement with results of other parallel studies comparing the performance of AAA with PBC (Basran et al 2010, Yoo et al 2012, Bufacchi et al 2013, Petillion et al 2014). It is interesting to note that although small, the differences between predictions of the two algorithms were statistically significant in many cases. Furthermore, the results in Paper I were different for the two subgroups (WBO and BSC), highlighting the difficulties in extrapolating findings of subgroup analyses, similar to the difficulties in extrapolating findings from various tumour sites (Bufacchi et al 2013).

The results could also be discussed from the perspective of the target or the involved OAR. Thus, maintaining the current standard of care would require a relaxation of the requirements for target homogeneity to reflect the predictions of the AAA. Indeed, relaxing the criteria for target homogeneity has been included in the latest set of recommendations from the Swedish radiotherapy group (Blom Goldman et al 2014) in comparison to the older set of recommendations listed in Table I of Paper II. The results in Paper I also showed that the average dose to the target is smaller for AAA calculations than for PBC calculations and therefore maintaining the requirement for average dose to the target would in turn increase the doses to the OAR. Nevertheless, in many cases the dosimetric parameters for plan acceptance are lower than the tolerance criteria for the OAR involved and could accommodate a possible increase in OAR doses.

Similar considerations regarding dose distributions from AAA also apply for the OAR. Thus, it was found that AAA could lead to higher hotspots, which were sometimes near sensitive structures such as the brachial plexus. Johansson et al (2002b) previously reported $4 \%$ brachial plexus neuropathies at 5 years and $12 \%$ at 30 years for equivalent doses in 2 Gy fractions of about $63 \mathrm{~Gy}$. These dose levels are equivalent with those from a dose hotspot of about $125 \%$ of the prescription dose for either of the fractionation regimes currently employed for irradiating patients for breast cancer and from this perspective this topic deserves further investigations. Nevertheless, such an investigation, which is beyond the purpose of the present study, is time consuming and needs specific knowledge to delineate the involved structure for accurate dose response characterisation.

Statistically significant differences were also found for the ipsilateral lung and for the heart. Thus, both the mean dose and the volume of tissue receiving more than 20 Gy $\left(\mathrm{V}_{20}\right.$ Gy $)$ for the lung were significantly higher with AAA than with $\mathrm{PBC}$, although the absolute change was rather small. Higher differences were found for the volume receiving more than $10 \mathrm{~Gy}\left(\mathrm{~V}_{10 \mathrm{~Gy}}\right)$ which is thought to correlate with radiological changes in the lung (Blom Goldman 2010) and this 
indicates that further studies are needed to characterise the sensitivity of the lung around these doses.

The results also showed that the mean dose to the heart was significantly lower in AAA calculations than in PBC calculations, by $13 \%$ in BSC patients and by $22 \%$ in $\mathrm{WBO}$ patients. The range of individual values was rather broad, $4-22 \%$ in BSC and $4-44 \%$ in WBO. These findings reflect the situation of the normal tissue complication probabilities for the lung where AAA required significantly different model parameters than PBC (Bufacchi et al 2013, Hedin and Back 2013, Petillion et al 2014). Indeed, our findings indicate that the heart could be $13-22 \%$ more sensitive that thought based on PBC findings. Based on PBC calculations (Taylor et al 2009, Taylor et al 2011), a large case-control study reported a few years back that heart irradiation from radiotherapy for breast cancer could increase the risk for major coronary events by $7.4 \% \mathrm{~Gy}^{-1}$ with no threshold (Darby et al 2013). Nevertheless, this rate is affected by some uncertainties. Thus the $95 \%$ confidence interval $(2.9-14.5 \%)$ indicates a possible variation of the sensitivity by a factor of two in either direction. Furthermore, the heart doses were not original patient doses, but were derived from reconstructions of the treatment plans from the various techniques employed since the 1950s adding further uncertainties to the estimated rate of complications. Further analyses of the predicted differences in heart sensitivity are therefore warranted and careful attention should be paid to the algorithm used for dose calculation. Such considerations on tolerance levels could become the basis for future revisions of the recommendations to maintain the current balance between local control and complications in the normal tissue. Our results also suggest that pooling results from several centres using different dose calculation algorithms will be fraught with uncertainties regarding the actual dose received.

The change of the irradiation patterns and the decrease of radiation doses to the heart and other OAR from modern irradiation techniques (Brown et al 2015) has produced lower complication rates than in historical cohorts (Henson et al 2013). From this perspective it might be better to limit the analyses to the patient subgroups that are at higher risk for developing complications, either from increased radiation burden from standard techniques or from coexisting morbidities. Such subgroups are rather small in the case of breast cancer patients, but they might require dedicated treatment techniques that could further reduce the doses to the OAR for an acceptable target coverage. Papers II-IV in the present project used this approach, studying the potential for the reduction of dose burden and hence the probability for normal tissue complications using improved techniques for irradiation or patient monitoring. The investigated techniques are the irregular surface compensator (Paper II), proton therapy (Paper III) and respiratory gating techniques (Paper IV).

The irregular surface compensator that was the topic in Paper II uses dynamic MLC to improve dose homogeneity for breast radiotherapy. All patients included in this study were different from the average patient since they had heter- 
ogeneous dose distributions in the target or existing lung comorbidities that required maintaining the radiation burden to this organ as low as possible. For these reasons, this was a rather small group of patients, but it was considered suitable for a preliminary report from the first 10 patients investigating the potential for improvement that could be achieved with the ISC technique. The results showed that ISC could be used to improve dose homogeneity in the target, but the improvement in target coverage with the $93 \%$ isodose failed to reach statistical significance, probably due to the size of the investigated population. With respect to the OAR, the ISC showed potential to reduce the lung burden, with the difference in $\mathrm{V}_{20 \text { Gy }}$ being on the borderline of statistical significance. The results also showed a tendency for ISC to increase cardiovascular burden. These results are in line with those from a recent study investigating only WBO patients (Hideki et al 2013). While a direct comparison with the WBO subgroup cannot be attempted due to the size of this subgroup in Paper II, it is worth mentioning that the inclusion of patients requiring ISC continues and a new analysis will be attempted after more patients have been included in the different subgroups. It should also be mentioned that the original patient cohort included both WBO and BSC patients which may have diluted some of the expected results, as these subgroups have different patterns of radiation burden as shown for example in Paper I. While ISC has potential for a small group of patients, the advantages of using the technique for all patients is questionable since the standard 3D-CRT is capable of reducing the dose burden for many patients in the general breast cancer population (Brown et al 2015). The future analysis on a larger group of patients will hopefully provide more information on the potential of ISC.

The need for further improvement of the dose distributions in the patient cohort in Paper II had also motivated the comparison with scanned beam proton therapy that made the subject of Paper III. The low number of included patients should be born in mind when trying to interpret the results and prognosticate future advantages of proton therapy. Proton therapy with scanning beams has recently become available at the Skandion Clinic, the national proton therapy centre in Sweden. The comparison in Paper III has shown that protons have a significant potential for improving target coverage and reducing the normal tissue burden. However the analysis of the subgroup of patients with left-side disease only neared statistical significance in many instances. Therefore, the potential of protons has also been investigated on the larger number of free-breathing patients in Paper IV and the new analysis confirmed the dosimetric parameters and findings in Paper III, with improved statistical significance. These findings are also in agreement with other studies investigating the potential of scanned proton beams for locoregional treatment for breast cancer (Ares et al 2010, Jimenez et al 2013). It is interesting to note that both Paper III and Paper IV showed a significant potential for the protons to reduce the mean dose to the heart and the LAD. This should be taken into account for the selection of future breast cases for proton therapy in Sweden. The results also showed that protons could reduce the lung 
burden for locoregional treatments. In contrast, for whole breast treatments protons showed a tendency towards increasing the low-dose component of ipsilateral lung. Also, protons showed potential for reducing the integral dose in comparison to photon techniques, with the largest effect for locoregional treatments where large volumes of normal tissue are irradiated with the latter techniques.

Figure 1. Comparison of lung dosimetric parameters (mean and standard deviation) in photon plans in enhanced inspiration gating (EIG) and proton plans in free breathing (FB). Upper panels - WBO patients; lower panels - BSC patients.
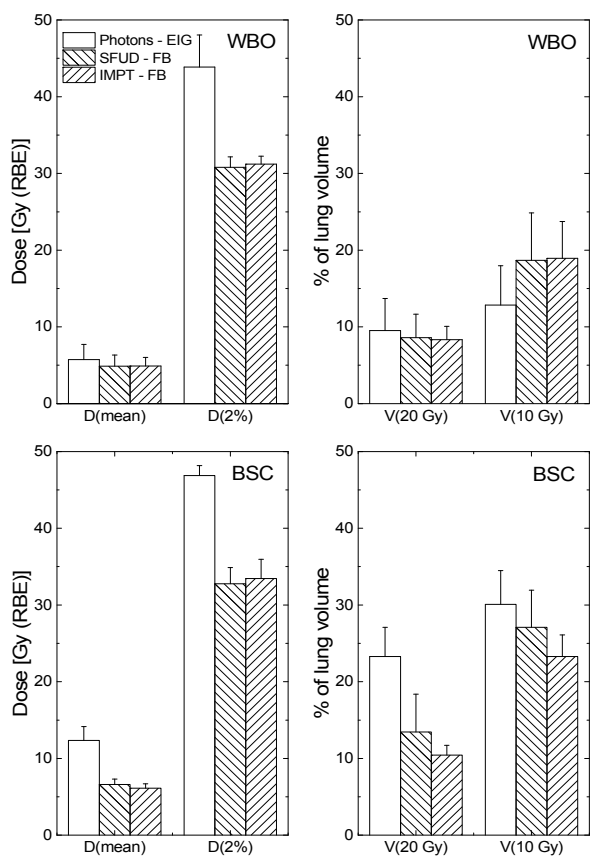

Normal tissue sparing could also be achieved for photon radiotherapy techniques through monitoring the breathing of the patients and irradiating in the phases of the breathing cycle that offer a good separation of the target and normal tissues (i.e., through respiratory gated radiotherapy). The added advantage of this approach for proton therapy has been investigated in Paper IV. The results of this comparison showed that proton treatments could improve target coverage and reduce normal tissue burden and the integral dose in both gated and free breathing patients. These results are comparable with and add to those from recent similar studies that only investigated whole breast treatments (Mast et al 2014, Lin et al 2015). 
The cross comparison between photon plans with EIG and proton plans in free breathing mode showed that protons could still provide a dosimetric advantage for the lungs (Figure 1), highlighting the potential of this treatment modality. However, the potential for cardiovascular sparing (Figure 2) varied and protons were only as good as the best sparing that could be achieved in photon EIG radiotherapy. Taking into account the estimated cost of the two treatment modalities, these results suggest that gated photon radiotherapy should be a first option in the attempt to reduce the radiation burden to the heart and the LAD.

Figure 2. Comparison of cardiovascular dosimetric parameters (mean and standard deviation) in photon plans in enhanced inspiration gating (EIG) and proton plans in free breathing (FB). Left panels - WBO patients; right panels - BSC patients.
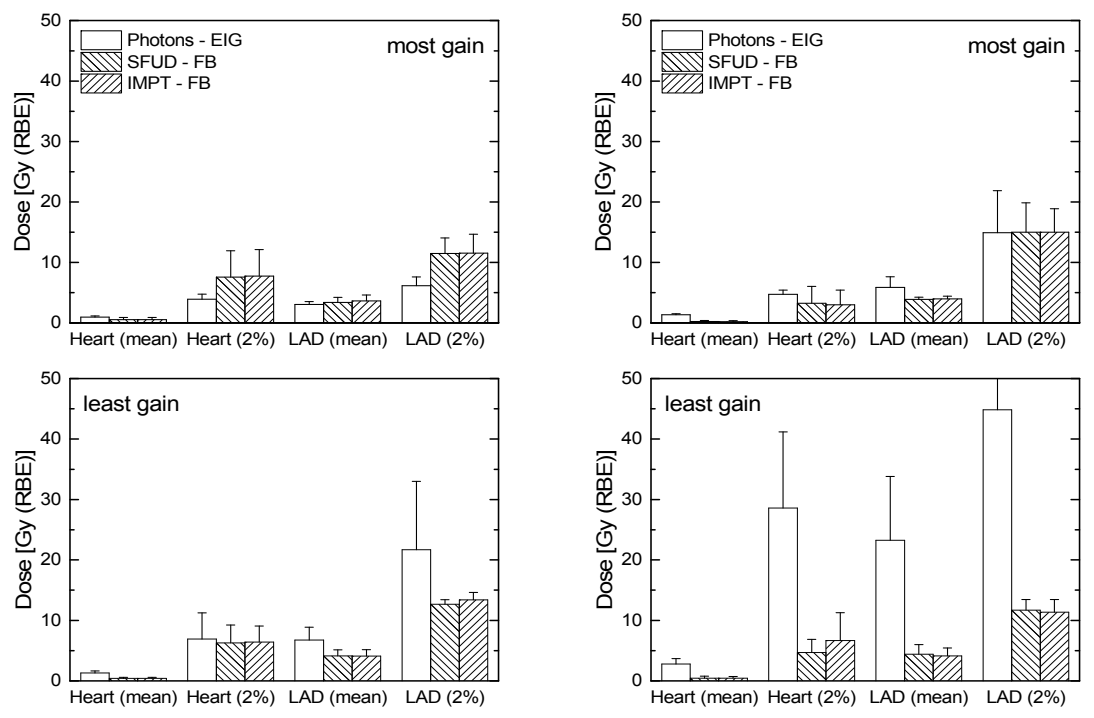

The interaction between breathing motion and the limited range of protons is one of the uncertainties that have to be considered with respect to proton therapy for breast cancer. The impact of this aspect has been studied in Paper V as only one other study exists on this topic (Ares et al 2010). The results indicated that breathing motion during proton breast radiotherapy determines a degradation of target coverage and could also affect the dose distributions in the OAR. Most differences were seen for the lung, where exhalation tended to decrease the lung burden, while inhalation increased it. Smaller differences were seen for the dosimetric parameters characterising the burden to the heart and the LAD. Nevertheless, the absolute changes were very small and therefore their expected clinical 
impact is also quite small, thus supporting the potential advantages of proton therapy for breast cancer.

At present there are no national guidelines for using protons for breast cancer radiotherapy, but the findings of these studies could help in the selection of the appropriate groups. Thus, women with heart or coronary disease, women with unfavourable anatomy that would otherwise increase the radiation burden for photon therapy (e.g., severe scoliosis or pectus excavatum) or women which do not comply with the requirements of respiratory gating could be candidates for radiation therapy with protons. Patients with severe lung damage that should undergo locoregional therapy might also be suitable candidates for proton radiotherapy.

Although focused on breast cancer patients, the individual studies of this project have offered valuable insights into the impact of anatomical variations on dose burden from radiation therapy as well as on the factors influencing the attempts to decrease the doses to the normal tissues. These could be used for the individualisation of breast cancer treatment that can ultimately improve the quality of life for this group of patients. 


\section{GENERAL CONCLUSIONS}

AAA should be preferred over the PBC algorithm for breast cancer radiotherapy as it gives more realistic dose distributions. Although small, the differences between dosimetric parameters are statistically significant. This suggests that normal tissue complication parameters might have to be revised to reflect the observed rates of complications.

Other irradiation techniques like the ISC or proton therapy should be considered as clinically useful alternatives for breast cases that require particularly high homogeneity of the dose to the target, such as patients with multifocal or lobular cancer and especially the sub-group that requires irradiation of the supraclavicular lymph nodes. These techniques could also be used to reduce the radiation burden to organs at risk.

The respiratory gating technique could be considered as a clinically useful alternative for patients with left-sided breast cancer that require particularly high dose to the target, especially the subgroup that requires irradiation of the supraclavicular and axillary lymph nodes. Proton spot scanning may reduce normal tissue burden in both free breathing and enhanced inspiration gating, thus having increased potential to improve the quality of life of the patients after radiation therapy.

The impact of physiological breathing motion during proton radiotherapy for breast cancer is small as the differences in the delivered doses between inhalation and exhalation are very small.

These findings could be carefully extrapolated to other patient groups helping in the process of individualising radiation therapy in order to maximise tumour response and minimise the risk for complications. 


\section{FUTURE PROJECTS}

\subsection{Monitoring cardiac side effects from radio- therapy to the left mammary gland}

Limiting the doses to the normal tissues could be an effective approach to reduce the risk of complications. However, as shown by the results of this project, the degree of sparing is not the same for all patients and therefore monitoring the changes induced early by the treatment could provide additional information on the patients at risk for developing complications that could be referred to preventive strategies before the changes become too severe. From this perspective a study has been initiated to investigate the early pattern of appearance of changes in the cardiac function in breast cancer patients undergoing radiotherapy. The study employs new imaging technologies that could quantify the minute changes in physiological function and could also shed some light upon the underlying mechanisms that determine these changes. The study has been approved by the regional ethical review board in Linköping (2013/10-31, 2015/144-32).

\subsubsection{Patient cohort and study design}

The project aims to include at least 20 breast cancer patients undergoing radiation therapy to investigate the temporal and spatial patterns of cardiac side effects induced by radiation treatment for breast cancer and correlate with cardiovascular dosimetry. Patient accrual has been low, mainly due to patients having difficulties in tolerating the schedule of additional investigations and therefore only nine patients are available for analysis at this point. Each patient was repeatedly imaged with ultrasonography and magnetic resonance to assess the function of the myocardium at several time points during or after the treatment. An initial baseline investigation was performed before the start of treatment to evaluate the function of the unirradiated myocardium. A second investigation was performed during the second week of radiation therapy and reflects the earliest tissue response evaluation. Three other investigations followed, immediately after the completion of the therapy and then at 6 months and after 12 months post-therapy to evaluate the short- and long-term response. All patients received standard radiotherapy, although the standard changed during the progress of the study from 25 fractions of 2 Gy to 16 fractions of 2.66 Gy for treatment to the breast only. The heart, the left ventricle and the LAD were delineated for each patient and dosimetric parameters were derived for these structures. The study investigated mostly left-sided patients, but right-sided patients after anthracycline therapy have also been included in the comparison. This subgroup will hopefully offer information on their cardiovascular radiation burden (OAR structures are not de- 
lineated in these cases), as well as on the equivalent effects from the use of anthracyclines in breast cancer patients. Future correlation with cardiac MRI results will also offer insights into the mechanisms of appearance of cardiac complications from radiotherapy.

\subsubsection{Monitoring heart function during treatment}

Cardiac monitoring is performed with a multimodality approach using:

a) Strain rate imaging (US-SRI), an echocardiographic technique capable of quantifying the deformation properties of the myocardium;

b) Cardiac magnetic resonance imaging (C-MRI), capable of investigating myocardial function, oedema and the development of interstitial fibrosis.

Echocardiography is an attractive technique for monitoring treatmentinduced cardiac toxicity (Kongbundansuk and Hundley 2014). In particular, ultrasound-based strain rate imaging (US-SRI) can quantify the deformation properties of the myocardium, thus enabling a subtle evaluation of segmental myocardial function. Speckle tracking (Figure 3) detects the local deformation of cardiac muscle that can be recalculated as "strain" which can be thought of as representing the relative length change of the myocardium, as well as the rate at which the length changes, in different segments of the heart. This technique has been proven useful in cardiology patients and has been proposed as a candidate for surveillance in oncology.

Figure 3. Speckle tracking for strain measurements in the left ventricle at Linköping University Hospital.

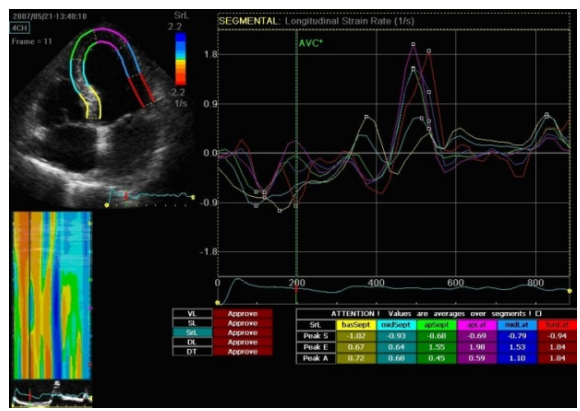

Tissue characterisation by $\mathrm{T} 1$ and $\mathrm{T} 2$-mapping cardiac magnetic resonance imaging (Figure 4) has recently been developed at Linköping University to visualise fibrosis and oedema in the left ventricle by measuring the spin-spin relaxation in inversion recovery sequences (Kindberg et al 2012, Kvernby et al 2014). This is the first attempt to use the technique for monitoring radiation side effects such as oedema and loss of pumping function in oncology patients. 
Figure 4. Magnetic resonance imaging of cardiac oedema at Linköping University Hospital.

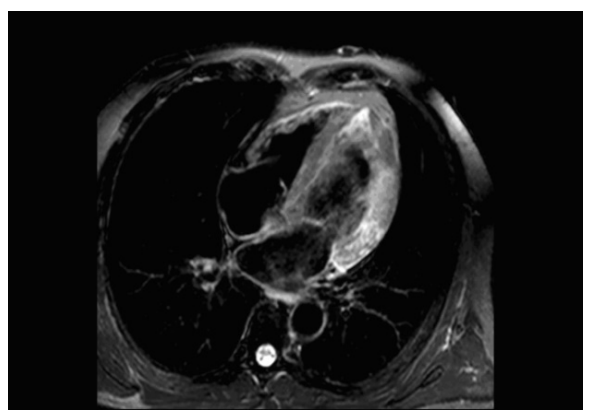

The aim is to use these techniques to monitor cardiac function to assess temporal changes in breast cancer patients undergoing radiation therapy.

\subsubsection{Preliminary results}

The preliminary results from the patients available at this time point show a post-treatment loss of cardiac systolic function measured as strain determined with echocardiography. The investigated population at this point is however too small to seek correlations with the radiation burden to the cardiac structures. Nevertheless, preliminary analyses have yielded negative Spearman's rank correlation coefficients (Figures 5-7) suggesting a possible inverse correlation between strain reduction and radiation dose.

Figure 5. Reduction in peak systolic myocardial strain at 12 months post-therapy as a function of the mean radiation dose to the left ventricle

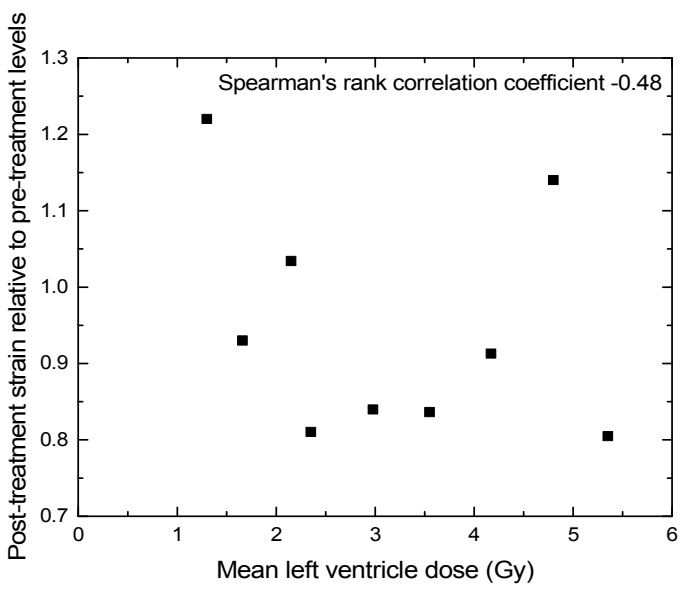


Figure 6. Reduction in peak systolic myocardial strain at 12 months post-therapy as a function of the mean radiation dose to the heart

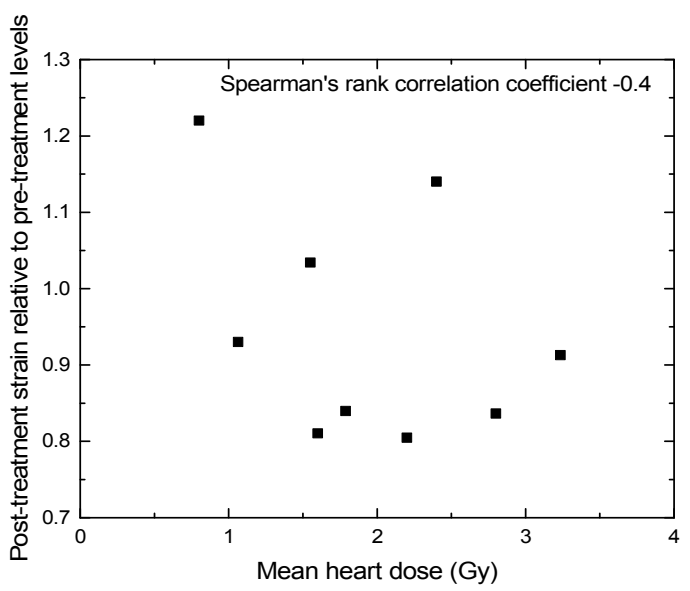

Figure 7. Reduction in peak systolic myocardial strain at 12 months post-therapy as a function of the near maximum radiation dose to the heart

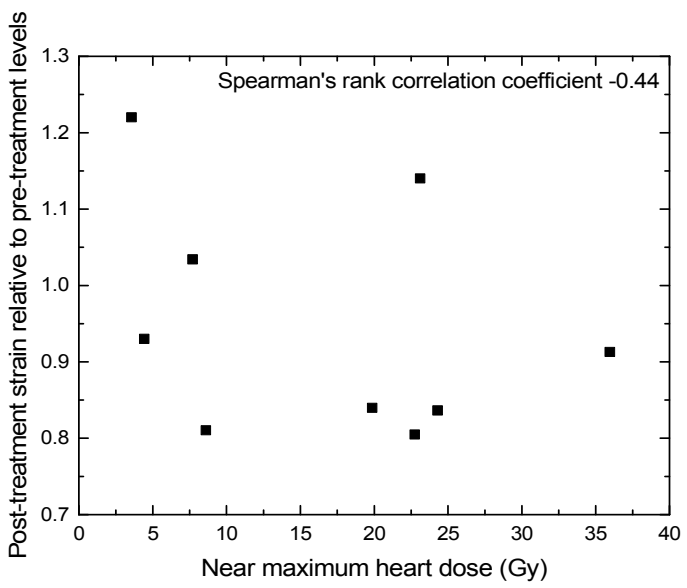

Further analysis will focus on the detection of oedema by MRI T1 and T2 mapping and investigate whether the intensity of oedema correlates with the received amount of radiation to the left ventricle. 


\subsection{Normal tissue sparing at internal mammary nodes treatment with proton radiation therapy}

Another study has been initiated to investigate the normal tissue burden from the treatment of internal mammary nodes (IMN) in breast cancer radiotherapy using scanned proton beams with or without respiratory gating. The study used CT-datasets acquired from ten left-sided patients during enhanced inspiration gating (EIG) and free-breathing (FB). The patients were planned with intensity modulated proton therapy (IMPT) for loco-regional breast treatment. The prescribed dose to the target was 50 Gy (RBE) in 25 fractions, assuming an RBE of 1.1. Different plans were produced for breast plus axillary and supraclavicular nodes respectively breast plus axillary, supraclavicular and internal mammary nodes. The doses to the organs at risk for cardiopulmonary complications were analysed for each group separately.

Preliminary results showed that the inclusion of the IMN in the target volume leads to a small increase of the cardiopulmonary burden. In free-breathing cases the average dose to the heart increased from 0.3 to $0.4 \mathrm{~Gy}$ (RBE) and the average dose to the lung increased from 6.1 to 6.6 Gy (RBE), while the average dose to the LAD decreased from 4.1 to $3.8 \mathrm{~Gy}$ (RBE). For enhanced inspiration gating cases the average dose to the heart was almost unchanged (0.2 Gy RBE), the average dose to the lung increased from 6.9 to $7.4 \mathrm{~Gy}(\mathrm{RBE})$ and the average dose to the LAD decreased from 3.3 to $2.6 \mathrm{~Gy}$ (RBE). The results indicate that scanned proton beams offer the possibility of including the internal mammary lymph nodes in the target for breast cancer radiotherapy without a significant increase of the risk for cardiovascular toxicity and only with a small increase of the risk for pulmonary toxicity, independently of the use of respiratory gating during the treatment. Also, the use of EIG for the treatment of IMN with scanned proton beams does not bring a significant advantage in reducing the cardiopulmonary burden. 


\section{ACKNOWLEDGEMENTS}

I would like to express my thanks to all who have served advice and assistance in my research, especially my supervisor Alexandru Dasu and my cosupervisors Gunnar Adell, Jan Engvall, Olle Stål and Margaretha Stenmarker, but also to the subject representative Charlotta Dabrosin. They were always available when needed.

I would like to express my gratitude to my family, my friends and all others for theirs support and help when I needed it most. 


\section{REFERENCES}

American Cancer Society 2016, Breast cancer guide [Internet], Available from: http://www.cancer.org/cancer/breastcancer/detailedguide/index.

Amir, E., Seruga, B., Niraula, S., Carlsson, L., \& Ocana, A. 2011, "Toxicity of adjuvant endocrine therapy in postmenopausal breast cancer patients: a systematic review and meta-analysis", Journal of the National Cancer Institute, vol. 103, no. 17, pp. 12991309.

Ares, C., Khan, S., Macartain, A. M., Heuberger, J., Goitein, G., Gruber, G., Lutters, G., Hug, E. B., Bodis, S., \& Lomax, A. J. 2010, "Postoperative proton radiotherapy for localized and locoregional breast cancer: potential for clinically relevant improvements?", International Journal of Radiation Oncology Biology Physics, vol. 76, no. 3, pp. 685697.

Arriagada, R., de Guevara, J. C., Mouriesse, H., Hanzen, C., Couanet, D., Ruffie, P., Baldeyrou, P., Dewar, J., Lusinchi, A., \& Martin, M. 1989, "Limited small cell lung cancer treated by combined radiotherapy and chemotherapy: evaluation of a grading system of lung fibrosis", Radiotherapy and Oncology, vol. 14, no. 1, pp. 1-8.

Bartelink, H., Horiot, J. C., Poortmans, P. M., Struikmans, H., Van den, B. W., Fourquet, A., Jager, J. J., Hoogenraad, W. J., Oei, S. B., Warlam-Rodenhuis, C. C., Pierart, M., \& Collette, L. 2007, "Impact of a higher radiation dose on local control and survival in breast-conserving therapy of early breast cancer: 10-year results of the randomized boost versus no boost EORTC 22881-10882 trial", J.Clin.Oncol., vol. 25, no. 22, pp. 3259-3265.

Basran, P. S., Zavgorodni, S., Berrang, T., Olivotto, I. A., \& Beckham, W. 2010, "The impact of dose calculation algorithms on partial and whole breast radiation treatment plans", Radiation Oncology, vol. 5, 120.

Bentzen, S. M., Constine, L. S., Deasy, J. O., Eisbruch, A., Jackson, A., Marks, L. B., Ten Haken, R. K., \& Yorke, E. D. 2010, "Quantitative Analyses of Normal Tissue Effects in the Clinic (QUANTEC): an introduction to the scientific issues", International Journal of Radiation Oncology Biology Physics, vol. 76, no. 3 Suppl, pp. S3-S9.

Björk-Eriksson, T. \& Glimelius, B. 2005, "The potential of proton beam radiation therapy in breast cancer", Acta Oncologica, vol. 44, no. 8, pp. 884-889.

Blom Goldman, U., Wennberg, B., Svane, G., Bylund, H., \& Lind, P. 2010, "Reduction of radiation pneumonitis by V20-constraints in breast cancer", Radiation Oncology, vol. 5, p. 99.

Blom Goldman, U., Hällje, M., Kjéllen, L., Pålsson, Y., Sartz, A., \& Ärlig, Å. 2014, Riktlinjer för volymer och teknik vid strålbehandling av brostcancer (version 3) 
[Internet], Available from: http://www.swebcg.se/index.asp?P=Teknik-vidstralbehandling.

Bonilla, L., Ben Aharon, I., Vidal, L., Gafter-Gvili, A., Leibovici, L., \& Stemmer, S. M. 2010, "Dose-dense chemotherapy in nonmetastatic breast cancer: a systematic review and meta-analysis of randomized controlled trials", Journal of the National Cancer Institute, vol. 102, no. 24, pp. 1845-1854.

Bovelli, D., Plataniotis, G., \& Roila, F. 2010, "Cardiotoxicity of chemotherapeutic agents and radiotherapy-related heart disease: ESMO Clinical Practice Guidelines", Annals of Oncology, vol. 21 Supp1 5, p. v277-v282.

Bragg, C. M. \& Conway, J. 2006, "Dosimetric verification of the anisotropic analytical algorithm for radiotherapy treatment planning", Radiotherapy and Oncology, vol. 81, no. 3, pp. 315-323.

Bray, F., Ren, J. S., Masuyer, E., \& Ferlay, J. 2013, "Global estimates of cancer prevalence for 27 sites in the adult population in 2008", International Journal of Cancer, vol. 132 , no. 5, pp. 1133-1145.

Brosius, F. C., III, Waller, B. F., \& Roberts, W. C. 1981, "Radiation heart disease. Analysis of 16 young (aged 15 to 33 years) necropsy patients who received over 3,500 rads to the heart", Am.J.Med., vol. 70, no. 3, pp. 519-530.

Brown, L. C., Mutter, R. W., \& Halyard, M. Y. 2015, "Benefits, risks, and safety of external beam radiation therapy for breast cancer", International Journal of Women's Health, vol. 7, pp. 449-458.

Bufacchi, A., Nardiello, B., Capparella, R., \& Begnozzi, L. 2013, "Clinical implications in the use of the PBC algorithm versus the AAA by comparison of different NTCP models/parameters", Radiation Oncology, vol. 8, no. 1, p. 164.

Bush, D. A., Slater, J. D., Garberoglio, C., Yuh, G., Hocko, J. M., \& Slater, J. M. 2007, "A technique of partial breast irradiation utilizing proton beam radiotherapy: comparison with conformal x-ray therapy", Cancer Journal, vol. 13, no. 2, pp. 114-118.

Carabe, A., Moteabbed, M., Depauw, N., Schuemann, J., \& Paganetti, H. 2012, "Range uncertainty in proton therapy due to variable biological effectiveness", Physics in Medicine and Biology, vol. 57, no. 5, pp. 1159-1172.

Caudell, J. J., De Los Santos, J. F., Keene, K. S., Fiveash, J. B., Wang, W., Carlisle, J. D., \& Popple, R. 2007, "A dosimetric comparison of electronic compensation, conventional intensity modulated radiotherapy, and tomotherapy in patients with early-stage carcinoma of the left breast", International Journal of Radiation Oncology Biology Physics, vol. 68, no. 5, pp. 1505-1511.

Chui, C. S., Hong, L., Hunt, M., \& McCormick, B. 2002, "A simplified intensity modulated radiation therapy technique for the breast", Medical Physics, vol. 29, no. 4, pp. 522-529.

Chung, Y., Yoon, H. I., Kim, Y. B., Ahn, S. K., Keum, K. C., \& Suh, C. O. 2012, "Radiation pneumonitis in breast cancer patients who received radiotherapy using the par- 
tially wide tangent technique after breast conserving surgery", Journal of Breast Cancer, vol. 15, no. 3, pp. 337-343.

Clarke, M., Collins, R., Darby, S., Davies, C., Elphinstone, P., Evans, V., Godwin, J., Gray, R., Hicks, C., James, S., MacKinnon, E., McGale, P., McHugh, T., Peto, R., Taylor, C., \& Wang, Y. 2005, "Effects of radiotherapy and of differences in the extent of surgery for early breast cancer on local recurrence and 15-year survival: an overview of the randomised trials", Lancet, vol. 366, no. 9503, pp. 2087-2106.

Cox, J. D., Stetz, J., \& Pajak, T. F. 1995, "Toxicity criteria of the Radiation Therapy Oncology Group (RTOG) and the European Organization for Research and Treatment of Cancer (EORTC)", International Journal of Radiation Oncology Biology Physics, vol. 31 , no. 5 , pp. 1341-1346.

Cserni, G., Bori, R., Sejben, I., Voros, A., Kaiser, L., Hamar, S., Csorgo, E., \& Kulka, J. 2013, "Unifocal, multifocal and diffuse carcinomas: a reproducibility study of breast cancer distribution", Breast, vol. 22, no. 1, pp. 34-38.

Cuzick, J., Stewart, H., Rutqvist, L., Houghton, J., Edwards, R., Redmond, C., Peto, R., Baum, M., Fisher, B., Host, H., Lythgoe, J., Ribeiro, G., \& Scheurlen, H. 1994, "Causespecific mortality in long-term survivors of breast cancer who participated in trials of radiotherapy", J.Clin.Oncol., vol. 12, no. 3, pp. 447-453.

Darby, S. C., Ewertz, M., McGale, P., Bennet, A. M., Blom-Goldman, U., Bronnum, D., Correa, C., Cutter, D., Gagliardi, G., Gigante, B., Jensen, M. B., Nisbet, A., Peto, R., Rahimi, K., Taylor, C., \& Hall, P. 2013, "Risk of ischemic heart disease in women after radiotherapy for breast cancer", New England Journal of Medicine, vol. 368, no. 11, pp. 987-998.

Darby, S., McGale, P., Correa, C., Taylor, C., Arriagada, R., Clarke, M., Cutter, D., Davies, C., Ewertz, M., Godwin, J., Gray, R., Pierce, L., Whelan, T., Wang, Y., \& Peto, R. 2011, "Effect of radiotherapy after breast-conserving surgery on 10-year recurrence and 15-year breast cancer death: meta-analysis of individual patient data for 10,801 women in 17 randomised trials", Lancet, vol. 378, no. 9804, pp. 1707-1716.

Darby, S. C., McGale, P., Taylor, C. W., \& Peto, R. 2005, "Long-term mortality from heart disease and lung cancer after radiotherapy for early breast cancer: prospective cohort study of about 300,000 women in US SEER cancer registries", Lancet Oncology, vol. 6 , no. 8 , pp. 557-565.

Dasu, A. \& Toma-Dasu, I. 2013, "Impact of variable RBE on proton fractionation", Medical Physics, vol. 40, no. 1, p. 011705.

Dasu, A. \& Toma-Dasu, I. 2014, "Long-term effects and secondary tumors," in Comprehensive Biomedical Physics, Volume 9: Radiation Therapy Physics and Treatment Optimization, vol. 9 A. Brahme, ed., Elsevier, Amsterdam, pp. 223-233.

Davies, C., Godwin, J., Gray, R., Clarke, M., Cutter, D., Darby, S., McGale, P., Pan, H. C., Taylor, C., Wang, Y. C., Dowsett, M., Ingle, J., \& Peto, R. 2011, "Relevance of breast cancer hormone receptors and other factors to the efficacy of adjuvant tamoxifen: patient-level meta-analysis of randomised trials", Lancet, vol. 378, no. 9793, pp. 771784. 
DeVita Jr., V. T., Lawrence, T. S., \& Rosenberg, S. A. 2014, Cancer: Principles \& Practice of Oncology, 10 edn, Wolters Kluwer Health, Philadelphia.

Dorr, W. \& Hendry, J. H. 2001, "Consequential late effects in normal tissues", Radiotherapy and Oncology, vol. 61, no. 3, pp. 223-231.

Emami, B., Lyman, J., Brown, A., Coia, L., Goitein, M., Munzenrider, J. E., Shank, B., Solin, L. J., \& Wesson, M. 1991, "Tolerance of normal tissue to therapeutic irradiation", International Journal of Radiation Oncology Biology Physics, vol. 21, no. 1, pp. 109122.

Emmens, D. J. \& James, H. V. 2010, "Irregular surface compensation for radiotherapy of the breast: correlating depth of the compensation surface with breast size and resultant dose distribution", British Journal of Radiology, vol. 83, no. 986, pp. 159-165.

Engholm, G., Ferlay, J., Christensen, N., Bray, F., Gjerstorff, M. L., Klint, A., Kotlum, J. E., Olafsdottir, E., Pukkala, E., \& Storm, H. H. 2010, "NORDCAN--a Nordic tool for cancer information, planning, quality control and research", Acta Oncologica, vol. 49, no. 5 , pp. $725-736$.

Engholm, G., Ferlay, J., Christiansen, N., Kejs, A. M. T., Johannesen, T. B., Khan, S., Leinonen, M. K., Milter, M. C., Olafsdottir, E., Pettersen, T., Trykker, H., \& Storm, H. H. 2015, NORDCAN: Cancer Incidence, Mortality, Prevalence and Survival in the Nordic Countries, Version 7.2 (16.12.2015). Association of the Nordic Cancer Registries. Danish Cancer Society [Internet], Association of the Nordic Cancer Registries. Danish Cancer Society. Available from: http://www.ancr.nu.

Erven, K., Florian, A., Slagmolen, P., Sweldens, C., Jurcut, R., Wildiers, H., Voigt, J. U., \& Weltens, C. 2013, "Subclinical cardiotoxicity detected by strain rate imaging up to 14 months after breast radiation therapy", International Journal of Radiation Oncology Biology Physics, vol. 85, no. 5, pp. 1172-1178.

Ewer, M. S. \& Gluck, S. 2009, "A woman's heart: the impact of adjuvant endocrine therapy on cardiovascular health", Cancer, vol. 115, no. 9, pp. 1813-1826.

Fajardo, L. F. \& Stewart, J. R. 1973, "Pathogenesis of radiation-induced myocardial fibrosis", Laboratory Investigation, vol. 29, no. 2, pp. 244-257.

Ferlay, J., Soerjomataram, I., Ervik, M., Dikshit, R., Eser, S., Mathers, C., Rebelo, M., Parkin, D. M., Forman, D., \& Bray, F. 2013, GLOBOCAN 2012 v1.0: Cancer incidence and mortality worldwide: IARC CancerBase No. 11 [Internet], International Agency for Research on Cancer, Lyon, France. Available from: http://globocan.iarc.fr.

Fisher, B., Anderson, S., Bryant, J., Margolese, R. G., Deutsch, M., Fisher, E. R., Jeong, J. H., \& Wolmark, N. 2002, "Twenty-year follow-up of a randomized trial comparing total mastectomy, lumpectomy, and lumpectomy plus irradiation for the treatment of invasive breast cancer", New England Journal of Medicine, vol. 347, no. 16, pp. 12331241.

Fournier-Bidoz, N., Kirova, Y., Campana, F., El Barouky, J., Zefkili, S., Dendale, R., Bollet, M. A., Mazal, A., \& Fourquet, A. 2009, "Technique alternatives for breast radia- 
tion oncology: Conventional radiation therapy to tomotherapy", Journal of Medical Physics, vol. 34, no. 3, pp. 149-152.

Gagliardi, G., Lax, I., Ottolenghi, A., \& Rutqvist, L. E. 1996, "Long-term cardiac mortality after radiotherapy of breast cancer--application of the relative seriality model", British Journal of Radiology, vol. 69, no. 825, pp. 839-846.

Gagliardi, G., Constine, L. S., Moiseenko, V., Correa, C., Pierce, L. J., Allen, A. M., \& Marks, L. B. 2010, "Radiation dose-volume effects in the heart", International Journal of Radiation Oncology Biology Physics, vol. 76, no. 3 Suppl, p. S77-S85.

Gerweck, L. E. \& Kozin, S. V. 1999, "Relative biological effectiveness of proton beams in clinical therapy", Radiotherapy and Oncology, vol. 50, no. 2, pp. 135-142.

Goldhirsch, A., Winer, E. P., Coates, A. S., Gelber, R. D., Piccart-Gebhart, M., Thurlimann, B., \& Senn, H. J. 2013, "Personalizing the treatment of women with early breast cancer: highlights of the St Gallen International Expert Consensus on the Primary Therapy of Early Breast Cancer 2013", Annals of Oncology, vol. 24, no. 9, pp. 2206-2223.

Haviland, J. S., Owen, J. R., Dewar, J. A., Agrawal, R. K., Barrett, J., Barrett-Lee, P. J., Dobbs, H. J., Hopwood, P., Lawton, P. A., Magee, B. J., Mills, J., Simmons, S., Sydenham, M. A., Venables, K., Bliss, J. M., \& Yarnold, J. R. 2013, "The UK Standardisation of Breast Radiotherapy (START) trials of radiotherapy hypofractionation for treatment of early breast cancer: 10-year follow-up results of two randomised controlled trials", Lancet Oncology, vol. 14, no. 11, pp. 1086-1094.

Hedin, E. \& Back, A. 2013, "Influence of different dose calculation algorithms on the estimate of NTCP for lung complications", Journal of Applied Clinical Medical Physics, vol. 14, no. 5, pp. 127-139.

Hennequin, C., Bossard, N., Servagi-Vernat, S., Maingon, P., Dubois, J. B., Datchary, J., Carrie, C., Roullet, B., Suchaud, J. P., Teissier, E., Lucardi, A., Gerard, J. P., Belot, A., Iwaz, J., Ecochard, R., \& Romestaing, P. 2013, "Ten-year survival results of a randomized trial of irradiation of internal mammary nodes after mastectomy", International Journal of Radiation Oncology Biology Physics, vol. 86, no. 5, pp. 860-866.

Henson, K. E., McGale, P., Taylor, C., \& Darby, S. C. 2013, "Radiation-related mortality from heart disease and lung cancer more than 20 years after radiotherapy for breast cancer", British Journal of Cancer, vol. 108, no. 1, pp. 179-182.

Hideki, F., Nao, K., Hiroyuki, H., Hiroshi, K., \& Haruyuki, F. 2013, "Improvement of dose distribution with irregular surface compensator in whole breast radiotherapy", Journal of Medical Physics, vol. 38, no. 3, pp. 115-119.

Hjelstuen, M. H., Mjaaland, I., Vikstrom, J., \& Dybvik, K. I. 2012, "Radiation during deep inspiration allows loco-regional treatment of left breast and axillary-, supraclavicular- and internal mammary lymph nodes without compromising target coverage or dose restrictions to organs at risk", Acta Oncologica, vol. 51, no. 3, pp. 333-344.

Hooning, M. J., Botma, A., Aleman, B. M., Baaijens, M. H., Bartelink, H., Klijn, J. G., Taylor, C. W., \& van Leeuwen, F. E. 2007, "Long-term risk of cardiovascular disease in 
10-year survivors of breast cancer", Journal of the National Cancer Institute, vol. 99, no. 5 , pp. $365-375$.

Hundley, W. G., Bluemke, D. A., Finn, J. P., Flamm, S. D., Fogel, M. A., Friedrich, M. G., Ho, V. B., Jerosch-Herold, M., Kramer, C. M., Manning, W. J., Patel, M., Pohost, G. M., Stillman, A. E., White, R. D., \& Woodard, P. K. 2010, "ACCF/ACR/AHA/NASCI/SCMR 2010 expert consensus document on cardiovascular magnetic resonance: a report of the American College of Cardiology Foundation Task Force on Expert Consensus Documents", Journal of the American College of Cardiolo$g y$, vol. 55, no. 23, pp. 2614-2662.

IARC 2012, "Personal habits and indoor combustions. Volume 100 E. A review of human carcinogens", IARC Monographs on the Evaluation of Carcinogenic Risks to Humans, vol. 100, no. Pt E, pp. 1-538.

ICRU 1993, Prescribing, recording, and reporting photon beam therapy, International Commission on Radiation Units and Measurements, Bethesda, ICRU Report 50.

ICRU 1999, Prescribing, recording and reporting photon beam therapy, International Commission on Radiation Units and Measurements, Bethesda, ICRU Report 62.

ICRU 2004, Prescribing, recording, and reporting electron beam therapy, International Commission on Radiation Units and Measurements, Bethesda, ICRU Report 71.

ICRU 2007, Prescribing, recording, and reporting proton-beam therapy, International Commission on Radiation Units and Measurements, Bethesda, ICRU Report 78.

ICRU 2010, Prescribing, recording, and reporting photon-beam intensity-modulated radiation therapy (IMRT), International Commission on Radiation Units and Measurements, Bethesda, ICRU Report 83.

James, H. V., Scrase, C. D., \& Poynter, A. J. 2004, "Practical experience with intensitymodulated radiotherapy", British Journal of Radiology, vol. 77, no. 913, pp. 3-14.

James, M. L., Lehman, M., Hider, P. N., Jeffery, M., Hickey, B. E., \& Francis, D. P. 2010, "Fraction size in radiation treatment for breast conservation in early breast cancer", Cochrane Database of Systematic Reviews no. 11, p. CD003860.

Jassem, J. 1998, Rak sutka. Podrecznik dla studentów i lekarzy PWN, Warsaw.

Jimenez, R. B., Goma, C., Nyamwanda, J., Kooy, H. M., Halabi, T., Napolitano, B. N., McBride, S. M., Taghian, A. G., Lu, H. M., \& MacDonald, S. M. 2013, "Intensity modulated proton therapy for postmastectomy radiation of bilateral implant reconstructed breasts: a treatment planning study", Radiotherapy and Oncology, vol. 107, no. 2, pp. 213-217.

Johansson, J., Isacsson, U., Lindman, H., Montelius, A., \& Glimelius, B. 2002, "Nodepositive left-sided breast cancer patients after breast-conserving surgery: potential outcomes of radiotherapy modalities and techniques", Radiotherapy and Oncology, vol. 65, no. 2, pp. 89-98. 
Johansson, S., Svensson, H., \& Denekamp, J. 2002, "Dose response and latency for radiation-induced fibrosis, edema, and neuropathy in breast cancer patients", International Journal of Radiation Oncology Biology Physics, vol. 52, no. 5, pp. 1207-1219.

Kestin, L. L., Sharpe, M. B., Frazier, R. C., Vicini, F. A., Yan, D., Matter, R. C., Martinez, A. A., \& Wong, J. W. 2000, "Intensity modulation to improve dose uniformity with tangential breast radiotherapy: initial clinical experience", International Journal of Radiation Oncology Biology Physics, vol. 48, no. 5, pp. 1559-1568.

Kindberg, K., Haraldsson, H., Sigfridsson, A., Engvall, J., Ingels, N. B., Jr., Ebbers, T., \& Karlsson, M. 2012, "Myocardial strains from 3D displacement encoded magnetic resonance imaging", BMC Medical Imaging, vol. 12, p. 9.

Knoos, T., Wieslander, E., Cozzi, L., Brink, C., Fogliata, A., Albers, D., Nystrom, H., \& Lassen, S. 2006, "Comparison of dose calculation algorithms for treatment planning in external photon beam therapy for clinical situations", Physics in Medicine and Biology, vol. 51, no. 22 , pp. 5785-5807.

Kongbundansuk, S. \& Hundley, W. G. 2014, "Noninvasive imaging of cardiovascular injury related to the treatment of cancer", JACC: Cardiovascular Imaging, vol. 7, no. 8, pp. 824-838.

Korreman, S. S., Pedersen, A. N., Aarup, L. R., Nottrup, T. J., Specht, L., \& Nystrom, H. 2006, "Reduction of cardiac and pulmonary complication probabilities after breathing adapted radiotherapy for breast cancer", International Journal of Radiation Oncology Biology Physics, vol. 65, no. 5, pp. 1375-1380.

Kozak, K. R., Katz, A., Adams, J., Crowley, E. M., Nyamwanda, J. A., Feng, J. K., Doppke, K. P., DeLaney, T. F., \& Taghian, A. G. 2006, "Dosimetric comparison of proton and photon three-dimensional, conformal, external beam accelerated partial breast irradiation techniques", International Journal of Radiation Oncology Biology Physics, vol. 65 , no. 5 , pp. $1572-1578$.

Kvernby, S., Warntjes, M. J., Haraldsson, H., Carlhall, C. J., Engvall, J., \& Ebbers, T. 2014, "Simultaneous three-dimensional myocardial T1 and T2 mapping in one breath hold with 3D-QALAS", Journal of Cardiovascular Magnetic Resonance, vol. 16, p. 102.

Langen, K. M. \& Jones, D. T. 2001, "Organ motion and its management", International Journal of Radiation Oncology Biology Physics, vol. 50, no. 1, pp. 265-278.

LENT 1995, "LENT SOMA scales for all anatomic sites", International Journal of Radiation Oncology Biology Physics, vol. 31, no. 5, pp. 1049-1091.

Lin, L. L., Vennarini, S., Dimofte, A., Ravanelli, D., Shillington, K., Batra, S., Tochner, Z., Both, S., \& Freedman, G. 2015, "Proton beam versus photon beam dose to the heart and left anterior descending artery for left-sided breast cancer", Acta Oncologica, vol. 54, no. 7, pp. 1032-1039.

Lind, P. A., Wennberg, B., Gagliardi, G., \& Fornander, T. 2001, "Pulmonary complications following different radiotherapy techniques for breast cancer, and the association 
to irradiated lung volume and dose", Breast Cancer Research and Treatment, vol. 68, no. 3, pp. 199-210.

Litiere, S., Werutsky, G., Fentiman, I. S., Rutgers, E., Christiaens, M. R., Van Limbergen, E., Baaijens, M. H., Bogaerts, J., \& Bartelink, H. 2012, "Breast conserving therapy versus mastectomy for stage I-II breast cancer: 20 year follow-up of the EORTC 10801 phase 3 randomised trial", Lancet Oncology, vol. 13, no. 4, pp. 412-419.

Lomax, A. J., Cella, L., Weber, D., Kurtz, J. M., \& Miralbell, R. 2003, "Potential role of intensity-modulated photons and protons in the treatment of the breast and regional nodes", International Journal of Radiation Oncology Biology Physics, vol. 55, no. 3, pp. 785-792.

Lundkvist, J., Ekman, M., Ericsson, S. R., Jonsson, B., \& Glimelius, B. 2005, "Proton therapy of cancer: potential clinical advantages and cost-effectiveness", Acta Oncologi$c a$, vol. 44 , no. 8 , pp. 850-861.

MacDonald, S. M., Jimenez, R., Paetzold, P., Adams, J., Beatty, J., DeLaney, T. F., Kooy, H., Taghian, A. G., \& Lu, H. M. 2013, "Proton radiotherapy for chest wall and regional lymphatic radiation; dose comparisons and treatment delivery", Radiation Oncology, vol. 8, p. 71.

Marks, L. B., Bentzen, S. M., Deasy, J. O., Kong, F. M., Bradley, J. D., Vogelius, I. S., El Naqa, I., Hubbs, J. L., Lebesque, J. V., Timmerman, R. D., Martel, M. K., \& Jackson, A. 2010, "Radiation dose-volume effects in the lung", International Journal of Radiation Oncology Biology Physics, vol. 76, no. 3 Suppl, p. S70-S76.

Marwick, T. H. \& Narula, J. 2014, "Why, when, and how often?: The next steps after defining the right tools for noninvasive imaging of cardiotoxicity", JACC: Cardiovascular Imaging, vol. 7, no. 8, pp. 851-853.

Mast, M. E., Vredeveld, E. J., Credoe, H. M., van Egmond, J., Heijenbrok, M. W., Hug, E. B., Kalk, P., Kempen-Harteveld, L. M., Korevaar, E. W., van der Laan, H. P., Langendijk, J. A., Rozema, H. J., Petoukhova, A. L., Schippers, J. M., Struikmans, H., \& Maduro, J. H. 2014, "Whole breast proton irradiation for maximal reduction of heart dose in breast cancer patients", Breast Cancer Research and Treatment, vol. 148, no. 1, pp. 33-39.

McGale, P., Darby, S. C., Hall, P., Adolfsson, J., Bengtsson, N. O., Bennet, A. M., Fornander, T., Gigante, B., Jensen, M. B., Peto, R., Rahimi, K., Taylor, C. W., \& Ewertz, M. 2011, "Incidence of heart disease in 35,000 women treated with radiotherapy for breast cancer in Denmark and Sweden", Radiotherapy and Oncology, vol. 100, no. 2, pp. 167-175.

McGale, P., Taylor, C., Correa, C., Cutter, D., Duane, F., Ewertz, M., Gray, R., Mannu, G., Peto, R., Whelan, T., Wang, Y., Wang, Z., \& Darby, S. 2014, "Effect of radiotherapy after mastectomy and axillary surgery on 10 -year recurrence and 20 -year breast cancer mortality: meta-analysis of individual patient data for 8135 women in 22 randomised trials", Lancet, vol. 383, no. 9935, pp. 2127-2135.

Morris, A. D., Morris, R. D., Wilson, J. F., White, J., Steinberg, S., Okunieff, P., Arriagada, R., Le, M. G., Blichert-Toft, M., \& van Dongen, J. A. 1997, "Breast-conserving 
therapy vs mastectomy in early-stage breast cancer: a meta-analysis of 10-year survival", Cancer Journal from Scientific American, vol. 3, no. 1, pp. 6-12.

Nilsson, G. 2012, Cardiovascular side effects of radiotherapy in breast cancer, $\mathrm{PhD}$ thesis, Uppsala University.

Paszat, L. F., Mackillop, W. J., Groome, P. A., Boyd, C., Schulze, K., \& Holowaty, E. 1998, "Mortality from myocardial infarction after adjuvant radiotherapy for breast cancer in the surveillance, epidemiology, and end-results cancer registries", J.Clin.Oncol., vol. 16 , no. 8 , pp. $2625-2631$.

Perez, C. A. \& Brady, L. W. 1997, Principles and Practice of Radiation Oncology, 3 edn, Lippincott Williams and Wilkins, Philadelphia.

Petillion, S., Swinnen, A., Defraene, G., Verhoeven, K., Weltens, C., \& Van den, H. F. 2014, "The photon dose calculation algorithm used in breast radiotherapy has significant impact on the parameters of radiobiological models", Journal of Applied Clinical Medical Physics, vol. 15, no. 4, p. 4853.

Polgar, C., Van Limbergen, E., Potter, R., Kovacs, G., Polo, A., Lyczek, J., Hildebrandt, G., Niehoff, P., Guinot, J. L., Guedea, F., Johansson, B., Ott, O. J., Major, T., \& Strnad, V. 2010, "Patient selection for accelerated partial-breast irradiation (APBI) after breastconserving surgery: recommendations of the Groupe Europeen de CurietherapieEuropean Society for Therapeutic Radiology and Oncology (GEC-ESTRO) breast cancer working group based on clinical evidence (2009)", Radiotherapy and Oncology, vol. 94, no. 3, pp. 264-273.

Poortmans, P. M., Collette, S., Kirkove, C., Van Limbergen, E., Budach, V., Struikmans, H., Collette, L., Fourquet, A., Maingon, P., Valli, M., De Winter, K., Marnitz, S., Barillot, I., Scandolaro, L., Vonk, E., Rodenhuis, C., Marsiglia, H., Weidner, N., van Tienhoven, G., Glanzmann, C., Kuten, A., Arriagada, R., Bartelink, H., \& Van den Bogaert, W. 2015, "Internal mammary and medial supraclavicular irradiation in breast cancer", New England Journal of Medicine, vol. 373, no. 4, pp. 317-327.

Poortmans, P. M., Venselaar, J. L., Struikmans, H., Hurkmans, C. W., Davis, J. B., Huyskens, D., van Tienhoven, G., Vlaun, V., Lagendijk, J. J., Mijnheer, B. J., De Winter, K. A., Van der Hulst, M. H., \& Van den Bogaert, W. F. 2001, "The potential impact of treatment variations on the results of radiotherapy of the internal mammary lymph node chain: a quality-assurance report on the dummy run of EORTC Phase III randomized trial 22922/10925 in Stage I--III breast cancer(1)", International Journal of Radiation Oncology Biology Physics, vol. 49, no. 5, pp. 1399-1408.

Regionala cancercentrum i samverkan 2014, Bröstcancer - Nationellt vårdprogram.

Romestaing, P., Lehingue, Y., Carrie, C., Coquard, R., Montbarbon, X., Ardiet, J. M., Mamelle, N., \& Gerard, J. P. 1997, "Role of a 10-Gy boost in the conservative treatment of early breast cancer: results of a randomized clinical trial in Lyon, France", J.Clin.Oncol., vol. 15, no. 3, pp. 963-968.

Roychoudhuri, R., Robinson, D., Putcha, V., Cuzick, J., Darby, S., \& Moller, H. 2007, "Increased cardiovascular mortality more than fifteen years after radiotherapy for breast cancer: a population-based study", BMC.Cancer, vol. 7, p. 9. 
Schultz-Hector, S. \& Trott, K. R. 2007, "Radiation-induced cardiovascular diseases: is the epidemiologic evidence compatible with the radiobiologic data?", International Journal of Radiation Oncology Biology Physics, vol. 67, no. 1, pp. 10-18.

Shah, C., Badiyan, S., Berry, S., Khan, A. J., Goyal, S., Schulte, K., Nanavati, A., Lynch, M., \& Vicini, F. A. 2014, "Cardiac dose sparing and avoidance techniques in breast cancer radiotherapy", Radiotherapy and Oncology, vol. 112, no. 1, pp. 9-16.

Socialstyrelsen 2015, Cancerincidens i Sverige 2014. Nya diagnosticerade cancerfall år 2014 Socialstyrelsen, Stockholm.

Socialstyrelsen 2016, Screening för bröstcancer [Internet], Available from: http://www.socialstyrelsen.se/riktlinjer/nationellascreeningprogram/brostcancerscreeningmedmammog.

Storchi, P. \& Woudstra, E. 1996, "Calculation of the absorbed dose distribution due to irregularly shaped photon beams using pencil beam kernels derived from basic beam data", Physics in Medicine and Biology, vol. 41, no. 4, pp. 637-656.

Storchi, P. R., van Battum, L. J., \& Woudstra, E. 1999, "Calculation of a pencil beam kernel from measured photon beam data", Physics in Medicine and Biology, vol. 44, no. 12, pp. 2917-2928.

Suit, H., Delaney, T., Goldberg, S., Paganetti, H., Clasie, B., Gerweck, L., Niemierko, A., Hall, E., Flanz, J., Hallman, J., \& Trofimov, A. 2010, "Proton vs carbon ion beams in the definitive radiation treatment of cancer patients", Radiotherapy and Oncology, vol. 95 , no. 1, pp. 3-22.

Swedborg, I. \& Wallgren, A. 1981, "The effect of pre- and postmastectomy radiotherapy on the degree of edema, shoulder-joint mobility, and gripping force", Cancer, vol. 47, no. 5, pp. 877-881.

Taylor, C. W., Nisbet, A., McGale, P., Goldman, U., Darby, S. C., Hall, P., \& Gagliardi, G. 2009, "Cardiac doses from Swedish breast cancer radiotherapy since the 1950s", Radiotherapy and Oncology, vol. 90, no. 1, pp. 127-135.

Taylor, C. W., Bronnum, D., Darby, S. C., Gagliardi, G., Hall, P., Jensen, M. B., McGale, P., Nisbet, A., \& Ewertz, M. 2011, "Cardiac dose estimates from Danish and Swedish breast cancer radiotherapy during 1977-2001", Radiotherapy and Oncology, vol. 100, no. 2, pp. 176-183.

Tzonevska, A., Tzvetkov, K., Atanasova, M., Chakarova, A., \& Piperkova, E. 2011, "Myocardial scintigraphy, echocardiography and proBNP for early detection of myocardial cardiotoxicity in breast cancer patients after chemo-radiotherapy", Hellenic Journal of Nuclear Medicine, vol. 14, no. 3, pp. 269-273.

Ulmer, W., Pyyry, J., \& Kaissl, W. 2005, "A 3D photon superposition/convolution algorithm and its foundation on results of Monte Carlo calculations", Physics in Medicine and Biology, vol. 50, no. 8, pp. 1767-1790.

Vaidya, J. S., Joseph, D. J., Tobias, J. S., Bulsara, M., Wenz, F., Saunders, C., Alvarado, M., Flyger, H. L., Massarut, S., Eiermann, W., Keshtgar, M., Dewar, J., Kraus- 
Tiefenbacher, U., Sutterlin, M., Esserman, L., Holtveg, H. M., Roncadin, M., Pigorsch, S., Metaxas, M., Falzon, M., Matthews, A., Corica, T., Williams, N. R., \& Baum, M. 2010, "Targeted intraoperative radiotherapy versus whole breast radiotherapy for breast cancer (TARGIT-A trial): an international, prospective, randomised, non-inferiority phase 3 trial", Lancet, vol. 376, no. 9735, pp. 91-102.

Vaidya, J. S., Wenz, F., Bulsara, M., Tobias, J. S., Joseph, D. J., Keshtgar, M., Flyger, H. L., Massarut, S., Alvarado, M., Saunders, C., Eiermann, W., Metaxas, M., Sperk, E., Sutterlin, M., Brown, D., Esserman, L., Roncadin, M., Thompson, A., Dewar, J. A., Holtveg, H. M., Pigorsch, S., Falzon, M., Harris, E., Matthews, A., Brew-Graves, C., Potyka, I., Corica, T., Williams, N. R., \& Baum, M. 2014, "Risk-adapted targeted intraoperative radiotherapy versus whole-breast radiotherapy for breast cancer: 5-year results for local control and overall survival from the TARGIT-A randomised trial", Lancet, vol. 383, no. 9917, pp. 603-613.

Van Esch, A., Tillikainen, L., Pyykkonen, J., Tenhunen, M., Helminen, H., Siljamaki, S., Alakuijala, J., Paiusco, M., Lori, M., \& Huyskens, D. P. 2006, "Testing of the analytical anisotropic algorithm for photon dose calculation", Medical Physics, vol. 33, no. 11, pp. 4130-4148.

Veronesi, U., Orecchia, R., Maisonneuve, P., Viale, G., Rotmensz, N., Sangalli, C., Luini, A., Veronesi, P., Galimberti, V., Zurrida, S., Leonardi, M. C., Lazzari, R., Cattani, F., Gentilini, O., Intra, M., Caldarella, P., \& Ballardini, B. 2013, "Intraoperative radiotherapy versus external radiotherapy for early breast cancer (ELIOT): a randomised controlled equivalence trial", Lancet Oncology, vol. 14, no. 13, pp. 1269-1277.

Vikstrom, J., Hjelstuen, M. H., Mjaaland, I., \& Dybvik, K. I. 2011, "Cardiac and pulmonary dose reduction for tangentially irradiated breast cancer, utilizing deep inspiration breath-hold with audio-visual guidance, without compromising target coverage", Acta Oncologica, vol. 50, no. 1, pp. 42-50.

Walters, S., Benitez-Majano, S., Muller, P., Coleman, M. P., Allemani, C., Butler, J., Peake, M., Guren, M. G., Glimelius, B., Bergstrom, S., Pahlman, L., \& Rachet, B. 2015, "Is England closing the international gap in cancer survival?", British Journal of Cancer, vol. 113, no. 5, pp. 848-860.

Weber, D. C., Ares, C., Lomax, A. J., \& Kurtz, J. M. 2006, "Radiation therapy planning with photons and protons for early and advanced breast cancer: an overview", Radiation Oncology, vol. 1, p. 22.

Wedenberg, M., Lind, B. K., \& Hardemark, B. 2013, "A model for the relative biological effectiveness of protons: The tissue specific parameter alpha/beta of photons is a predictor for the sensitivity to LET changes", Acta Oncologica, vol. 52, no. 3, pp. 580588.

Wedenberg, M. \& Toma-Dasu, I. 2014, "Disregarding RBE variation in treatment plan comparison may lead to bias in favor of proton plans", Medical Physics, vol. 41, no. 9, p. 091706.

Whelan, T. J., Pignol, J. P., Levine, M. N., Julian, J. A., MacKenzie, R., Parpia, S., Shelley, W., Grimard, L., Bowen, J., Lukka, H., Perera, F., Fyles, A., Schneider, K., 
Gulavita, S., \& Freeman, C. 2010, "Long-term results of hypofractionated radiation therapy for breast cancer", New England Journal of Medicine, vol. 362, no. 6, pp. 513520.

Willett, C. G., Linggood, R. M., Stracher, M. A., Goitein, M., Doppke, K., Kushner, D. C., Morris, T., Pardy, J., \& Carroll, R. 1987, "The effect of the respiratory cycle on mediastinal and lung dimensions in Hodgkin's disease. Implications for radiotherapy gated to respiration", Cancer, vol. 60, no. 6, pp. 1232-1237.

Yoo, S., Wu, Q., O'Daniel, J., Horton, J., \& Yin, F. F. 2012, "Comparison of 3D conformal breast radiation treatment plans using the anisotropic analytical algorithm and pencil beam convolution algorithm", Radiotherapy and Oncology, vol. 103, no. 2, pp. $172-177$. 


\section{Articles}

The articles associated with this thesis have been removed for copyright reasons. For more details about these see:

http://urn.kb.se/resolve?urn=urn:nbn:se:liu:diva-127370 